\title{
TECHNOLOGY DIFFUSION: MEASUREMENT, CAUSES AND CONSEQUENCES
}

\author{
Diego A. Comin \\ Martí Mestieri \\ Working Paper 19052 \\ http://www.nber.org/papers/w19052
NATIONAL BUREAU OF ECONOMIC RESEARCH
1050 Massachusetts Avenue
Cambridge, MA 02138

May 2013

The views expressed herein are those of the authors and do not necessarily reflect the views of the National Bureau of Economic Research.

NBER working papers are circulated for discussion and comment purposes. They have not been peerreviewed or been subject to the review by the NBER Board of Directors that accompanies official NBER publications.

(C) 2013 by Diego A. Comin and Martí Mestieri. All rights reserved. Short sections of text, not to exceed two paragraphs, may be quoted without explicit permission provided that full credit, including $\odot$ notice, is given to the source. 
Technology Diffusion: Measurement, Causes and Consequences

Diego A. Comin and Martí Mestieri

NBER Working Paper No. 19052

May 2013

JEL No. E0,F0,N0,O0

\title{
ABSTRACT
}

This chapter discusses different approaches pursued to explore three broad questions related to technology diffusion: what general patterns characterize the diffusion of technologies, and how have they changed over time; what are the key drivers of technology, and what are the macroeconomic consequences of technology. We prioritize in our discussion unified approaches to these three questions that are based on direct measures of technology.

\author{
Diego A. Comin \\ Harvard Business School \\ Soldiers Field \\ Boston, MA 02163 \\ and NBER \\ dcomin@hbs.edu \\ Martí Mestieri \\ Toulouse School of Economics \\ Batiment F, MF503 \\ 21, Allée de Brienne \\ 31015 Toulouse \\ France \\ marti.mestieri@gmail.com
}




\title{
Technology Diffusion: \\ Measurement, Causes and Consequences
}

\author{
Diego Comin \\ Martí Mestieri \\ Harvard University, NBER and CEPR Toulouse School of Economics
}

May 8, 2013*

\section{Contents}

1 Introduction $\quad 4$

2 Measurement $\quad 5$

2.1 Extensive measures at the country level . . . . . . . . . . . . . . . 5

2.2 Traditional measures of technology diffusion . . . . . . . . . . . . 7

2.3 The intensive margin . . . . . . . . . . . . . . . . . . . 9

2.3 .1 Usage lags . . . . . . . . . . . . . . . . . . . . . . . 10

2.3.2 The shape of diffusion curves once the intensive margin is included . . . 11

2.3.3 A Microfoundation for the Diffusion Curve . . . . . . . . . . . . . . . 14

2.3.4 The intensive and extensive margin . . . . . . . . . . . . . 18

2.4 Other Approaches . . . . . . . . . . . . . . . . . . . 23

3 Drivers of Technology Adoption $\quad 24$

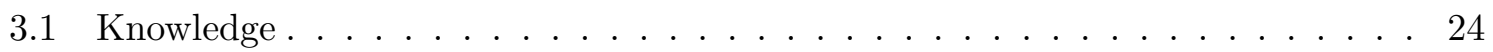

3.1 .1 Human capital . . . . . . . . . . . . . . . . . 25

3.1 .2 Adoption history . . . . . . . . . . . . . . . . . . . . . . . . . . . 30

3.1.3 Geographic interactions . . . . . . . . . . . . . . . . 30

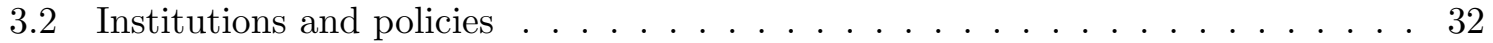

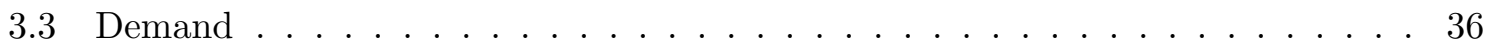

${ }^{*}$ This paper has been prepared for the Handbook of Economic Growth. Comin: dcomin@hbs.edu, Mestieri: marti.mestieri@tse-fr.eu 
4 Effects of Technology Adoption $\quad 38$

4.1 Business Cycles Fluctuations . . . . . . . . . . . . . . . . 39

4.1 .1 Shocks . . . . . . . . . . . . . . . . . 39

4.1 .2 Propagation mechanisms f . . . . . . . . . . . . . 40

4.2 Development . . . . . . . . . . . . . . . . . . 46

4.3 Growth . . . . . . . . . . . . . . . . . . . . 49

5 Concluding remarks $\quad 54$

A Description of Technologies used to Estimate Diffusion Curves 62

$\begin{array}{ll}\text { B Additional Tables } & 65\end{array}$

\begin{abstract}
This chapter discusses different approaches pursued to explore three broad questions related to technology diffusion: what general patterns characterize the diffusion of technologies, and how have they changed over time; what are the key drivers of technology, and what are the macroeconomic consequences of technology. We prioritize in our discussion unified approaches to these three questions that are based on direct measures of technology.
\end{abstract}




\section{Introduction}

tech·no·lo·gy, noun: a manner of accomplishing a task especially using technical processes, methods, or knowledge.

\section{- The Merriam-Webster's Collegiate Dictionary}

New technologies take the form of new production processes, new tools, and new and higher quality goods and services. Following the seminal work of Solow (1956), there is a wide consensus that advances in technology are a key source of economic growth over the long term. Many of these advances result, directly or indirectly, from purposeful investments in research and development $(\mathrm{R} \& \mathrm{D})$, as pointed out by the endogenous growth literature (e.g., Arrow, 1962, Romer, 1990, Aghion and Howitt, 1992).

$R \& D$ is not the only (or even the main) type of investment to upgrade technology. In fact, R\&D investments are concentrated in a few countries (e.g., Keller, 2004). The overwhelming majority of governments and companies around the world do not engage in any significant R\&D expenditures. Instead, most companies in the vast majority of countries are well behind the technology frontier. Their fundamental concern when upgrading their technology is to obtain access to better technologies that already exist but they do not use yet. Hence, it is very important to understand technology adoption patterns for companies and countries.

Technology diffusion is the dynamic consequence of adoption. It characterizes the accumulation of technology across adopters and over time, which arises from individual adoption decisions. This chapter discusses different approaches pursued to explore three broad questions related to technology diffusion: first, what the patterns of technology diffusion are, and how they have changed over time; second, what factors affect technology diffusion; and third, what the macroeconomic consequences of technology diffusion are.

Several vast literatures that expand various disciplines have addressed some of these questions. Therefore, it is impossible to make justice to all this work in just a chapter. Rather than focusing on being comprehensive in answering one question (which has been done elsewhere), ${ }^{1}$ we see greater value in presenting empirical strategies that have explored the three questions in a unified way. The other principle we use to guide our choice is to focus on works that use direct measures of technology. ${ }^{2}$ Because these conditions are restrictive, our chapter does not intend to be a comprehensive survey.

The chapter is organized in three sections that coincide with the three questions we have outlined. Section 2 describes various approaches followed to measure technology diffusion and discusses their value and shortcomings. We pay special attention to attempts made to explore

\footnotetext{
${ }^{1}$ See, for example, Metcalfe $(1981,1998)$, Stoneman (1983, 1987); Stoneman et al. (1995), Thirtle and Ruttan (1987), Karshenas and Stoneman (1993)), Vickery and Northcott (1995).

${ }^{2}$ See Coe and Helpman, 1995, and Keller, 2004 for analyses based on indirect technology measures.
} 
the evolution of adoption patterns over time as well as how they differ across countries. Section 3 explores factors identified as drivers of technology. Section 4 explores the macroeconomic consequences of technology, focusing mostly on how technology affects income dynamics at different frequencies. Section 5 concludes with some open questions for future research.

\section{Measurement}

Prior to studying diffusion patterns, we need to measure technology diffusion. The approaches developed to measure technology diffusion differ in terms of (i) the dimensions of technology they intend to measure and (ii) the level at which they try to measure diffusion. In this section, we describe different existing measures of diffusion, as well as the main lessons from each approach.

\subsection{Extensive measures at the country level}

Probably the simplest way to think about technology consists in tracking whether a specific technology is present or not in a given country at a moment in time. The data requirements to construct such measures are minimal. Country-level extensive measures are informative of the overall level of technology in a country if there is large cross-country variation in adoption lags. However, country-level extensive measures of adoption do not capture how intensively a technology is used once it is present in the country. As we show below, this condition makes country-level extensive measures of technology more relevant to study technology adoption patterns until around the beginning of the twentieth century.

We know from the work of Maddison (2004) that cross-country income differences were relatively small until the industrial revolution. How large were cross-country differences in technology adoption in the distant past? Comin et al. (2010) take on this question by assembling three data sets with country-level extensive measures of technology adoption. Each data set reports the adoption patterns of the inhabitants of modern day territories in different historical moments: 1000BC, 0AD and $1500 \mathrm{AD}$. The first two are coded using twelve technologies from the "Atlas of Cultural Evolution" (Peregrine, 2003). The data set for 1500 AD covers 24 technologies coded by Comin et al. (2010). The technologies considered satisfy three criteria. First, they were state of the art technologies (at the time considered); second, they were used in productive activities (i.e. activities that entered GDP); and third, it has been possible to document its presence or absence for a wide range of countries. In all three periods, the technologies can be classified in five broad sectors: agriculture, industry, transportation, communication and military. For each technology, the data set measures whether it was present (1) or absent (0) from the relevant territory in the relevant period of time. Comin et al. (2010) compute country-sector adoption levels as the simple average of the bi- 
Table 1: Descriptive statistics of Overall Technology Adoption by Continent

\begin{tabular}{|c|c|c|c|c|c|c|}
\hline \multirow{6}{*}{$\begin{array}{l}\text { Period } \\
1000 \mathrm{BC}\end{array}$} & Continent & Obs. & Average & Std. Dev. & Min & Max \\
\hline & Europe & 30 & 0.66 & 0.16 & 0.5 & 1 \\
\hline & Africa & 34 & 0.36 & 0.31 & 0 & 1 \\
\hline & Asia & 23 & 0.58 & 0.25 & 0.1 & 1 \\
\hline & America & 24 & 0.24 & 0.12 & 0 & 0.4 \\
\hline & Oceania & 2 & 0.2 & 0.14 & 0.1 & 0.3 \\
\hline \multicolumn{7}{|l|}{ 0AD } \\
\hline & Europe & 33 & 0.88 & 0.15 & 0.7 & 1 \\
\hline & Africa & 40 & 0.77 & 0.2 & 0.6 & 1 \\
\hline & Asia & 34 & 0.88 & 0.15 & 0.6 & 1 \\
\hline & America & 25 & 0.33 & 0.17 & 0 & 0.6 \\
\hline & Oceania & 3 & 0.17 & 0.11 & 0.1 & 0.3 \\
\hline $1500 \mathrm{AD}$ & Europe & 26 & 0.87 & 0.074 & 0.69 & 1 \\
\hline & Africa & 39 & 0.32 & 0.2 & 0.1 & 0.78 \\
\hline & Asia & 25 & 0.66 & 0.19 & 0.07 & 0.88 \\
\hline & America & 24 & 0.14 & 0.07 & 0 & 0.13 \\
\hline & Oceania & 9 & 0.12 & 0.04 & 0 & 0.13 \\
\hline
\end{tabular}

nary adoption values across the technologies in the sector. Then, the overall adoption level is computed as the simple average of the sectoral adoption levels.

Table 1 presents the variation across continents in overall technology adoption. In all three historical periods, Europe and Asia present the highest average levels of overall technology adoption, while America and Oceania present the lowest, with Africa in between. The range of variation in the average adoption levels across continents suggests that technological differences were significant despite the wide consensus that cross-country variation in living standards was limited until the nineteenth century (e.g., Maddison, 2004). Similarly, there was significant within continent variation in technology levels. Note that, given the binary nature of the underlying data, the maximum level the standard deviation can achieve is 0.5. The median standard deviation within continents (in all three periods) is 0.15 . Table 2 shows that the cross-country variation in technology is larger than the cross-continent variation with 
Table 2: Variation in technology adoption within countries vs. across countries

\begin{tabular}{|c|c|c|c|c|c|c|c|}
\hline \multirow[b]{2}{*}{ Period } & \multirow[b]{2}{*}{ Obs. } & \multirow{2}{*}{$\begin{array}{r}\text { STD. across } \\
\text { countries } \\
\text { Overall }\end{array}$} & \multicolumn{5}{|c|}{$\begin{array}{c}\text { STD. of deviations of sector } \\
\text { level technology from overall } \\
\text { technology adoption within countries }\end{array}$} \\
\hline & & & Agri. & Ind. & Military & Transp. & Comm. \\
\hline $1000 \mathrm{BC}$ & 114 & 0.28 & 0.35 & 0.18 & 0.16 & 0.22 & 0.23 \\
\hline 0 & 136 & 0.28 & 0.25 & 0.18 & 0.26 & 0.24 & 0.32 \\
\hline $1500 \mathrm{AD}$ & 125 & 0.32 & 0.2 & 0.19 & 0.13 & 0.12 & 0.17 \\
\hline
\end{tabular}

Note: STD. Overall is the cross-country standard deviation in overall technology adoption level. STD. of deviations of sector level technology from overall technology adoption is computed as follows: $\sigma(x s c t-x c t)$ where $\sigma(z)$ represents the standard deviation of $z$ across countries, $x s c t$ is the level of technology in sector $s$, country $c$, and period $t$, and $x c t$ denotes the overall adoption level in country $c$ in period $t$, the average of the adoption levels by sector for country $c$ in period $t$.

a level for the standard deviation close to 0.3 in all three periods.

Finally, one relevant empirical question is whether all variation in technology is captured by the variation in the average technology levels in the country or whether there is significant variation in technology across sectors (within a country). Table 2 explores this question. In particular, it reports the cross-country dispersion of the deviation between the sectoral and the overall adoption levels. This dispersion ranges from 0.12 to 0.35 with a median value of 0.2. These magnitudes suggest that a significant fraction of the variation in technology adoption is driven by within-country differences in technology across sectors.

\subsection{Traditional measures of technology diffusion}

It is possible to extend extensive measures of technology diffusion to more disaggregated levels to study how producers have access to a technology once it has arrived to a country. Let's suppose that potential adopters have a binary choice of whether to incur in a sunk cost of adopting the technology. After they incur in such a cost, they can use the technology indefinitely at no extra cost. Let's define $Y_{t}$ as

$$
Y_{t}=\frac{m_{t}}{M}
$$

where $M$ is the (fixed) number of potential adopters and $m_{t}$ is the number of producers that have adopted the technology at time $t$. This is how the diffusion literature has measured diffusion traditionally.

The traditional diffusion literature has fitted S-shaped diffusion curves (like the logistic function) to diffusion measures such as $Y_{t}$ (Griliches, 1957, Mansfield, 1961, Gort and Klepper, 
1982). For future reference, the logistic is defined by

$$
L_{t}=\frac{\delta_{1}}{1+e^{-\left(\delta_{2}+\delta_{3} t\right)}}
$$

where $t$ represents time, $\delta_{3}$ reflects the speed of adoption, $\delta_{2}$ is a constant of integration that positions the curve on the time scale, and $\delta_{1}$ is the long-run outcome.

Several features of this curve are relevant. The logistic curve summarizes the process of technology diffusion in just three parameters $\left(\delta_{1}, \delta_{2}\right.$ and $\left.\delta_{3}\right)$. It asymptotes to 0 when $t$ goes to minus infinity and to $\delta_{1}$ when $t$ goes to infinity. Finally, it is symmetric around the inflection point of $L_{t}=\delta_{1} / 2$ which occurs at $t=-\delta_{2} / \delta_{3}$.

Logistic or S-shaped curves have been fitted to technology measures such as (1) for technologies in many sectors and various countries. Examples of technologies explored in diffusion studies include the hybrid corn in U.S. states, Griliches (1957), $\beta$-blockers in U.S. states, Skinner and Staiger (2007), tetracycline among physicians in four U.S. cities, James S. Coleman and Menzel (1966), 22 manufacturing processes and machines in the UK (Davies, 1979), and various consumer durables in the U.S. (Cox and Alm, 1996). The main finding of the traditional diffusion literature is that S-shaped curves such as (2) provide a good fit to traditional diffusion measures of the form (1).

The slow initial pace that characterizes logistic diffusion patterns has motivated a number of theories about the drivers of diffusion. ${ }^{3}$ Epidemic models (e.g., Griliches, 1957, Mansfield, 1961, 1963, Romeo, 1975, Dixon, 1980, Davies, 1979, Levin et al., 1987 and Rose and Joskow, 1990) build on the premise that the lack of information on the technology prevents potential adopters from adopting profitable technologies. Information, in turn, is spread slowly because it only flows from those agents that have already adopted the technology. The so-called probit model builds on firms' heterogeneity in adoption costs or profits to generate heterogeneity in the timing of adoption. ${ }^{4}$ A third class of models that deliver S-shaped dynamics is based on the interaction of competition and legitimation forces (Hannan and Freeman, 1989). Legitimation is the process by which certain types of technologies become accepted as more agents adopt them. Competition forces limit the maximum level of diffusion as competition for resources limits the number of agents that an ecosystem can support. Finally, information cascades are another mechanism that may lead to S-shaped diffusion curves. In Banerjee (1992) and Arthur (1989), initially, agents may adopt slowly because they are experimenting with various technological options. After some initial precursors have decided to adopt one technology, followers may find optimal to copy their predecessors as in a herd leading to an acceleration of the speed of diffusion.

\footnotetext{
${ }^{3}$ See Geroski (2000) for an insightful survey and Skinner and Staiger (2007) for a review of the historical discussion as well as for some evidence to settle it.

${ }^{4}$ See for example, the vintage human capital of Chari and Hopenhayn (1991) for a beautiful example.
} 
Because most studies of technology diffusion that use traditional measures focus on one single technology and one or a few countries, traditional measures have not been able to shed light on significant general patterns in technology diffusion. One exception is Cox and Alm (1996) who show that in the U.S. the time it takes for $25 \%$ of potential adopters to adopt a technology (mostly consumer durables) has declined over the twentieth century.

\subsection{The intensive margin}

Despite its great intuitive appeal, traditional diffusion measures have two important drawbacks. First, their computation requires the use micro-level data sets which are hard to assemble. The limits imposed by this requirement may explain why, after 50 years of research, we still lack comprehensive data sets that cover the diffusion of many technologies, in many countries over protracted periods. Second, traditional diffusion measures do not capture the intensity with which each adopter uses the technology. ${ }^{5}$ For example, a company in the traditional measure will be coded as an adopter both when only one worker uses the technology and when all the workers have access to the technology. Similarly, traditional measures do not reflect how many units of a given technology a worker uses. Indeed, technological change is sometimes directed to increasing the number of technological goods that a worker can use at the same time. These concerns may be significant from a quantitative perspective. Clark (1987) shows that, circa 1910, the intensity of use of spindles and looms accounted for the bulk of cross-country productivity differences in cotton mills.

Since micro-level data sets do not tend to collect information on the intensity of use of technologies, it is difficult to extend traditional diffusion measures to include the intensive margin of adoption. An alternative approach consists in building these measures using country-level data. Comin and Hobijn (2004, 2009a) and Comin et al. (2006, 2008a) constructed the CHAT data set under this premise. CHAT covers the diffusion of 104 technologies (from most sectors of economic activity), for over 150 countries over the last 200 years. The measures of technology in CHAT are ratios for which the numerator reflect the intensity with which producers or consumers employ a technology at a given moment in time and the denominator scales that by the size of the economy (typically measured by the population or by GDP). For example, the diffusion of credit and debit cards is measured by the number of credit and debit card transactions per capita or by the number of points of service per capita, instead of by the share of people that has at least one credit card. Conceptually, a measure such as the number of card transactions per capita can be expressed as the product of two variables: The fraction of people with credit cards, and the average number of transactions of credit card users per user. The first variable captures the extent of diffusion of credit cards, while the second captures the intensity with which they are used once they have diffused.

\footnotetext{
${ }^{5}$ This is what Mansfield (1968), Davies (1979) and Stoneman (1981) call intra-firm diffusion.
} 
Because technology is often embodied in capital goods, some of the measures correspond to the number of specific capital goods per capita (e.g., computers and telephones). Other technologies take the form of new production techniques. In these cases, the technology is measured by the output produced with the technique per capita (e.g., tons of steel produced with electric arc furnaces per capita). One can make these measures unit free by taking the logs of the adoption ratios (i.e., log of number of MRI units per capita).

\subsubsection{Usage lags}

Measures of adoption that incorporate the intensive margin are hard to compare across technologies because they have different units. This difference in units makes it also difficult to assess the magnitude of the cross-country variation in technology and its comparison with cross-country differences in income. Comin et al. (2008b) transform cross-country differences in adoption intensity to time lags. Time lags have the advantage that they have a common unit across technologies, (e.g., years). They define the usage lag of technology $x$ in country $c$ at year $t$ as the answer to the following question: How many years before year $t$ did the United States last have a usage intensity of technology $x$ that country $c$ has in year $t ?^{6}$

For example, the amount of kWh of electricity (per capita) produced in Uruguay in 1990 was last observed in the United States in 1949. Thus, the electricity usage lag in Uruguay in 1990 is 41 years. Similarly, the number of personal computers per capita in Spain in 2002 was comparable to that in the United States in 1989. Hence, the 2002 PC usage lag of Spain is 13 years.

Comin et al. (2008b) compute the usage lags of 10 production technologies in periods where they are cutting-edge and for which CHAT covers at least 95 countries. These technologies include electricity production, transportation, communication, IT and agriculture. In addition, they also compute the time usage lags for per capita GDP. As illustrated by Figure 1, most of the world population is living in countries with real GDP per capita levels that have not been observed in the United States in the post World War II era. Moreover, most of Sub-Saharan Africa, as well as Afghanistan and Mongolia, have per-capita income levels that have not been observed in the United States since 1820.

With respect to technology usage lags, their main findings are that (i) Technology usage lags are large, often comparable to lags in real GDP per capita (ii) usage lags are highly correlated across countries with lags in per-capita income, and (iii) usage lags are highly correlated across technologies. These results are presented in Table 10) in the Appendix.

\footnotetext{
${ }^{6}$ An alternative way to deal with the differences in units is to take logarithms of the technology measures. This is the approach followed by much of the work discussed below.
} 
Figure 1: Real GDP per capita lags in year 2000

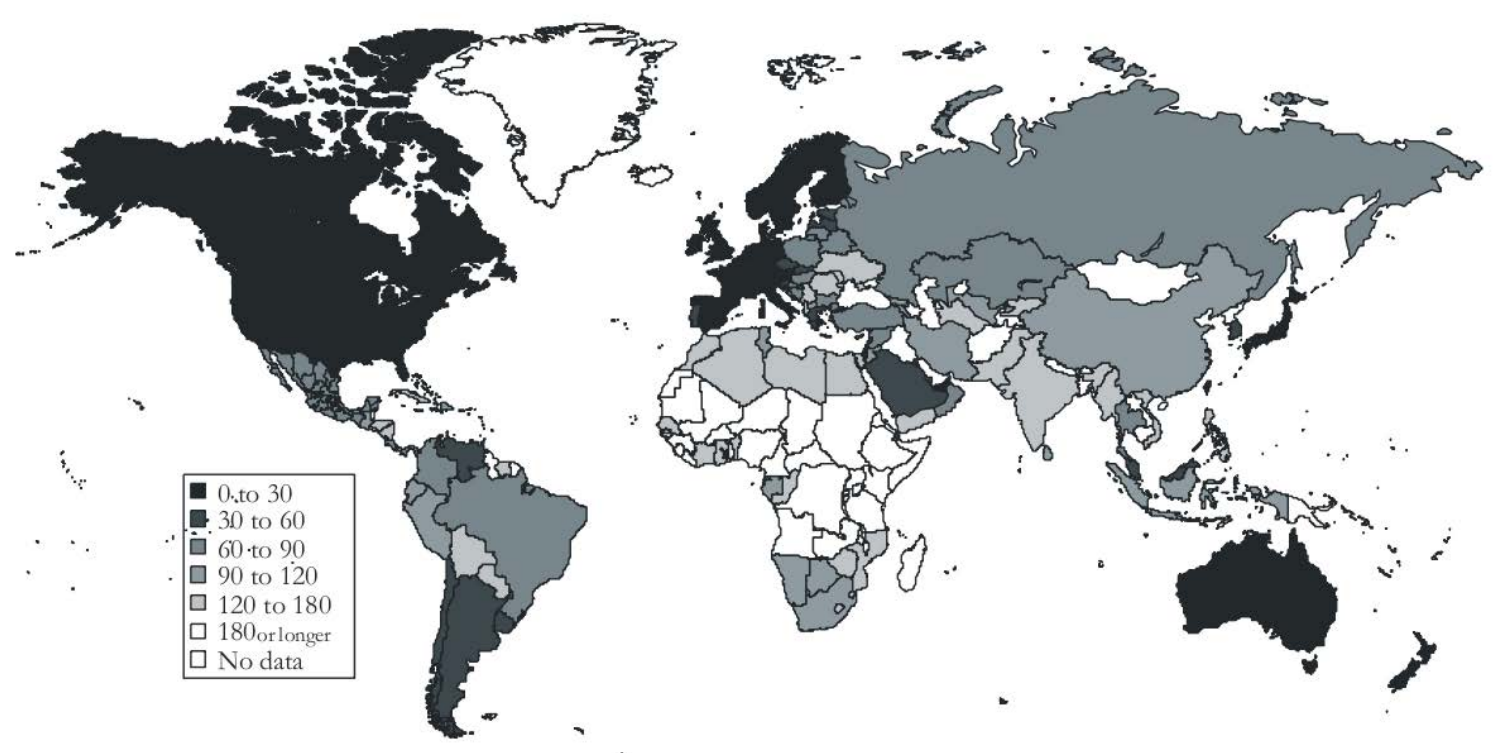

\subsubsection{The shape of diffusion curves once the intensive margin is included}

After documenting the magnitude of cross-country differences in technology adoption measures, one natural question is how do the measures of technology that incorporate the intensive margin evolve. In particular, do they follow a logistic curve?

Comin et al. (2008a) study this question using an early version of CHAT with 115 technologies that cover 5,678 technology-country pairs. ${ }^{7}$ They fit function (2) separately to each technology-country pair. For 1,291 cases it is not possible to fit the logistic curve due to the lack of curvature in the data since it covers the late stages of diffusion. For 466 cases, the estimate of the speed of diffusion $\left(\delta_{3}\right)$ is negative because the technology has become obsolete. $^{8}$

This leaves 3,921 technology-country cases where we can evaluate whether the logistic

\footnotetext{
${ }^{7}$ This version of CHAT included some measures of the diffusion of agricultural technologies (typically highyield seeds) measured as the fraction of agricultural land that used a specific high-yield variety. These series came from Evenson and Gollin (2003).

${ }^{8} \mathrm{~A}$ negative $\delta_{3}$ can result either from the substitution by a superior technology or because the logistic is a poor fit. To compute how many of the negative estimates of $\delta_{3}$ are due to the former, Comin et al. (2008a) recognize that the presence of competing technologies is likely to have similar effects in the estimates of $\delta_{3}$ across countries. Therefore, in those cases where the negative estimate of $\delta_{3}$ is produced by the replacement of a dominated technologies, we should observe a large number of negative estimates across countries. Comin et al. (2008a) find that 15 out of 115 technologies considered have negative estimates of $\delta_{3}$ for at least $50 \%$ of the technology-country pairs. They identify these as the cases where the estimates of $\delta_{3}$ are driven by the obsolescence of technology, and therefore are cleared from the count. These technologies include open hearth and Bessemer steel production and the number of sail ships, hospital beds, and checks, all of which have been dominated by another technology.
} 
Figure 2: Example of Diffusion Curve

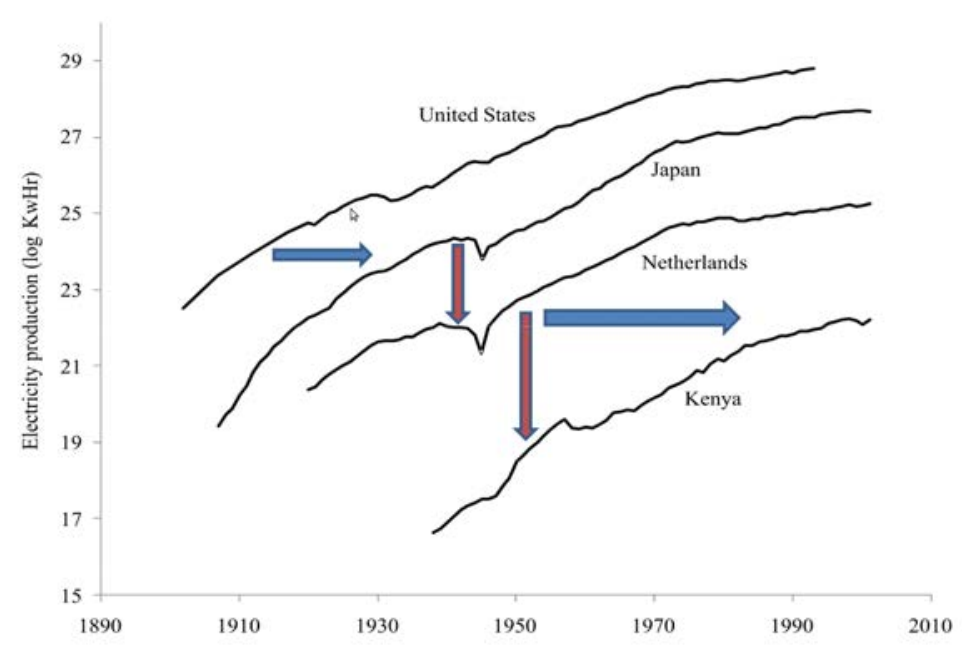

fits well the evolution of technology measures that include the intensive margin of adoption. For 454 cases, Comin et al. (2008a) still find a negative estimate of $\delta_{3}$ despite not being a dominated technology. This is, for example, the case of cars per capita in Tanzania, where population grew faster than the number of cars. For 202 cases, the predicted initial adoption is previous to the invention date of the technology. For 336 cases, the predicted adoption date is unrealistically late (either 150 years later that the invention of the technology or 20 years after the first for the country). Finally, 1,098 cases correspond to technologies that have a growing ceiling which contradicts the notion that $\delta_{1}$ is fixed. ${ }^{9}$ Adding these up, it turns out that for $53 \%$ of the technology-country cases $(2,084$ of 3,921$)$, the logistic does not provide a good fit to technology diffusion measures that incorporate the intensity of use.

So, if technology measures do not follow a logistic pattern, what do they follow? Figure 2 plots one typical technology measure in CHAT, the production of electricity measured as the log of MWh produced in the U.S., Japan, Netherlands and Kenya.

There are a number of features worth noting of these curves. First, they have a concave shape. Second, the shape of these curves is fairly similar. They look as if the same curve, say the one corresponding to the U.S., had been shifted left and down by different amounts. These two observations motivate us to conjecture that the curvature of the diffusion curve is related to technological characteristics common across countries, while horizontal and vertical shifts of the diffusion curves are informative about cross-country differences. One implication of this characterization of diffusion curves is that we just need two parameters to characterize differences across countries in the diffusion of a given technology.

\footnotetext{
${ }^{9}$ These include: steam and motor ship tonnage; rail passengers-kilometers; railway freight tonnage; tons of blast-oxygen furnace, electric-arc furnace, and stainless steel produced; cars; trucks; aviation freight tonkilometers; TVs; PCs; credit and debit card points of service; ATMs; and checkers.
} 
Of course, this raises two questions: How do we interpret these two shifters? And, how can they be identified in the data? Comin and Hobijn (2010) and Comin and Mestieri (2010) explore these two questions.

To start thinking about the shapes of diffusion curves, let $y_{\tau, t}^{c}$ denote the log-output produced with technology $\tau$ at time $t$ in country $c$. Based in the previous discussion about the shape of diffusion curves, one could conjecture that the diffusion curve could be approximately described by the following expression:

$$
y_{\tau, t}^{c}=\underbrace{\beta_{\tau 1}^{c}}_{\text {Vtcal Shift }}+\beta_{\tau 2} t+\beta_{\tau 3} \overbrace{\ln (t-\tau-\underbrace{\left.\beta_{\tau 4}^{c}\right)}_{\text {Hztal Shift }}}^{\text {Concave Shape }}+\varepsilon_{\tau t}^{c} .
$$

The left hand side is the log level of technology. The intercept $\beta_{\tau 1}^{c}$ captures the vertical shifts in the diffusion curve. We hypothesize a simple concave function such as the log function to introduce curvature in the diffusion curve, as can be seen in the third term of (3). The term inside the brackets, $t-\tau$, is the time elapsed since a technology has been invented (we denote a technology $\tau$ by its invention date). $\beta_{\tau 4}^{c}$ is a shifter of the concave curve. The larger $\beta_{\tau 4}^{c}$ is, the more to the right the diffusion curve shifts. Note that $\ln \left(t-\tau-\beta_{\tau 4}^{c}\right)$ is only well defined for $t-\tau-\beta_{\tau 4}^{c}>0$. Hence, a higher $\beta_{\tau 4}^{c}$ captures a delay in the arrival date of the technology $\tau$ to country $c$. Finally, we add a linear time trend that ensures that the technology measure asymptotically behaves log-linearly, as Figure 7 suggests.

This statistical characterization of the diffusion curves seems intuitive but it also raises some questions. For example, what role does income play in technology diffusion? A priori, there are two clear roles income can play in the diffusion measures contained in CHAT. First, richer countries should observe larger demand for the goods and services that embody or use technology. Hence, the Engel curve effect should induce a positive effect of income on technology. Second, the costs of producing the goods and services that embody technology tend to increase with the wage rate. Expression (3) ignores these effects. To incorporate them properly, it is necessary to develop a model of production and demand for technology. Next, we develop one such model based on Comin and Mestieri (2013). The model provides a microfoundation for a version of (3) as well as an interpretation for the vertical and horizontal shifters in Figure 2. In particular, it relates the horizontal shifts to the lag with which new vintages of technology (including the first one) on average arrive in a country. The vertical shifters capture the intensity (relative to GDP) with which the technology is used asymptotically. 


\subsubsection{A Microfoundation for the Diffusion Curve}

Consider the following economic environment. There is a unit measure of identical households in the economy. Each household supplies inelastically one unit of labor, for which they earn a wage $w$. Households can save in domestic bonds which are in zero net supply. The utility of the representative household is given by

$$
U=\int_{t_{0}}^{\infty} e^{-\rho t} \ln \left(C_{t}\right) d t
$$

where $\rho$ denotes the discount rate and $C$, consumption. The representative household, maximizes its utility subject to the budget constraint (5) and a no-Ponzi scheme condition (6)

$$
\begin{aligned}
& \dot{B}_{t}+C_{t}=w_{t}+r_{t} B_{t}, \\
& \lim _{t \rightarrow \infty} B_{t} e^{\int_{t_{0}}^{t}-r_{s} d s} \geq 0,
\end{aligned}
$$

where $B$ denotes the bond holdings of the representative consumer, $\dot{B}$ is the increase in bond holdings over an instant of time, and $r_{t}$ its return on bonds.

World technology frontier.- At a given instant of time, $t$, the world technology frontier is characterized by a set of technologies and a set of vintages specific to each technology. To simplify notation, we omit time subscripts, $t$, whenever possible. Each instant, a new technology, $\tau$, exogenously appears. We denote a technology by the time it was invented. Therefore, the range of invented technologies is $(-\infty, t]$.

For each existing technology, a new, more productive, vintage appears in the world frontier every instant. We denote vintages of technology- $\tau$ generically by $v_{\tau}$. Vintages are indexed by the time in which they appear. Thus, the set of existing vintages of technology- $\tau$ available at time $t(>\tau)$ is $[\tau, t]$. The productivity of a technology-vintage pair has two components. The first component, $Z\left(\tau, v_{\tau}\right)$, is common across countries and it is purely determined by technological attributes. In particular,

$$
\begin{aligned}
Z(\tau, v) & =e^{(\chi+\gamma) \tau+\gamma\left(v_{\tau}-\tau\right)} \\
& =e^{\chi \tau+\gamma v_{\tau}}
\end{aligned}
$$

where $(\chi+\gamma) \tau$ is the productivity level associated with the first vintage of technology $\tau$ and $\gamma\left(v_{\tau}-\tau\right)$ captures the productivity gains associated with the introduction of new vintages $\left(v_{\tau} \geq \tau\right){ }^{10}$

The second component is a technology-country specific productivity term, $a_{\tau}$, which we

\footnotetext{
${ }^{10}$ In what follows, whenever there is no confusion, we omit the subscript $\tau$ from the vintage notation and simply write $v$.
} 
further discuss below.

Adoption lags.- Economies typically are below the world technology frontier. Let $D_{\tau}$ denote the age of the best vintage available for production in a country for technology $\tau$. $D_{\tau}$ reflects the time lag between when the best vintage in use was invented and when it was adopted for production in the country; that is, the adoption lag. The set of technology- $\tau$ vintages available in this economy is $V_{\tau}=\left[\tau, t-D_{\tau}\right] .{ }^{11}$ Note that $D_{\tau}$ is both the time it takes for an economy to start using technology $\tau$ and its distance to the technology frontier in technology $\tau$.

Intensive margin.- New vintages $(\tau, v)$ are incorporated into production through new intermediate goods that embody them. Intermediate goods are produced competitively using one unit of final output to produce one unit of intermediate good.

Intermediate goods are combined with labor to produce the output associated with a given vintage, $Y_{\tau, v}$. In particular, let $X_{\tau, v}$ be the number of units of intermediate good $(\tau, v)$ used in production, and $L_{\tau, v}$ be the number of workers that use them to produce services. Then, $Y_{\tau, v}$ is given by

$$
Y_{\tau, v}=a_{\tau} Z(\tau, v) X_{\tau, v}^{\alpha} L_{\tau, v}^{1-\alpha} .
$$

The term $a_{\tau}$ in (9) represents factors that reduce the effectiveness of a technology in a country. These may include differences in the costs of producing the intermediate goods associated with a technology, taxes, relative abundance of complementary inputs or technologies, frictions in capital, labor and goods markets, barriers to entry for producers that want to develop new uses for the technology, etc. ${ }^{12}$ As we shall see below, $a_{\tau}$ determines the long-run penetration rate of the technology in the country. Hence, we refer to $a_{\tau}$ as the intensive margin of adoption of a technology.

Production.- The output associated with different vintages of the same technology can be combined to produce competitively sectoral output, $Y_{\tau}$, as follows

$$
Y_{\tau}=\left(\int_{\tau}^{t-D_{\tau}} Y_{\tau, v}^{\frac{1}{\mu}} d v\right)^{\mu}, \quad \text { with } \quad \mu>1
$$

Similarly, final output, $Y$, results from aggregating competitively the sectoral outputs $\left\{Y_{\tau}\right\}$ as follows

$$
Y=\left(\int_{-\infty}^{\bar{\tau}} Y_{\tau}^{\frac{1}{\theta}} d \tau\right)^{\theta}, \quad \text { with } \quad \theta>1
$$

where $\bar{\tau}$ denotes the most advanced technology adopted in the economy, that is the technology

\footnotetext{
${ }^{11}$ Here, we are assuming that vintage adoption is sequential. Comin and Hobijn (2010) provide a microfounded model in which this is an equilibrium result rather than an assumption.

${ }^{12}$ Comin and Mestieri (2010) discuss how a wide variety of distortions result in wedges in technology adoption that imply a reduced form as in (9).
} 
$\tau$ for which $\tau=t-D_{\tau}$.

\section{Factor Demands and Final Output}

We take the price of final output as numéraire. The demand for output produced with a particular technology is

$$
Y_{\tau}=Y p_{\tau}^{-\frac{\theta}{\theta-1}}
$$

where $p_{\tau}$ is the price of sector $\tau$ output. Both the income level of a country and the price of a technology affect the demand of output produced with a given technology. Because of the homotheticity of the production function, the income elasticity of technology $\tau$ output is one. Similarly, the demand for output produced with a particular technology vintage is

$$
Y_{\tau, v}=Y_{\tau}\left(\frac{p_{\tau}}{p_{\tau, v}}\right)^{-\frac{\mu}{\mu-1}}
$$

where $p_{\tau, v}$ denotes the price of the $(\tau, v)$ intermediate good. ${ }^{13}$ The demands for labor and intermediate goods at the vintage level are

$$
\begin{aligned}
(1-\alpha) \frac{p_{\tau, v} Y_{\tau, v}}{L_{\tau, v}} & =w \\
\alpha \frac{p_{\tau, v} Y_{\tau, v}}{X_{\tau, v}} & =1
\end{aligned}
$$

Perfect competition in the production of intermediate goods implies that the price of intermediate goods equals their marginal cost,

$$
p_{\tau, v}=\frac{w^{1-\alpha}}{Z(\tau, v) a_{\tau}}(1-\alpha)^{-(1-\alpha)} \alpha^{-\alpha}
$$

Combining (13), (14) and (15), the total output produced with technology $\tau$ can be expressed as

$$
Y_{\tau}=Z_{\tau} L_{\tau}^{1-\alpha} X_{\tau}^{\alpha}
$$

where $L_{\tau}$ denotes the total labor used in sector $\tau$,

$$
L_{\tau}=\int_{\tau}^{t-D_{\tau}} L_{\tau, v} d v,
$$

$X_{\tau}$ is the total amount of intermediate goods in sector $\tau$,

$$
X_{\tau}=\int_{\tau}^{t-D_{\tau}} X_{\tau, v} d v,
$$

\footnotetext{
${ }^{13}$ Even though older technology-vintage pairs are always produced in equilibrium, the value of its production relative to total output is declining over time.
} 
and the productivity associated to a technology is

$$
\begin{aligned}
Z_{\tau} & =\left(\int_{\tau}^{\max \left\{t-D_{\tau}, \tau\right\}} Z(\tau, v)^{\frac{1}{\mu-1}} d v\right)^{\mu-1} \\
& =\left(\frac{\mu-1}{\gamma}\right)^{\mu-1} \underbrace{a_{\tau}}_{\text {Intensive Mg }} \underbrace{e^{\left(\chi \tau+\gamma \max \left\{t-D_{\tau}, \tau\right\}\right)}}_{\text {Embodiment Effect }} \underbrace{\left(1-e^{\frac{-\gamma}{\mu-1}\left(\max \left\{t-D_{\tau}, \tau\right\}-\tau\right)}\right)^{\mu-1}}_{\text {Variety Effect }}
\end{aligned}
$$

This expression is quite intuitive. The productivity of a technology, $Z_{\tau}$, is determined by the intensive margin, the productivity level of the best vintage used (i.e., embodiment effect), and the productivity gains from using more vintages (i.e., variety effect). Adoption lags have two effects on $Z_{\tau}$. The shorter the adoption lags, $D_{\tau}$, the more productive are, on average, the vintages used. In addition, because there are productivity gains from using different vintages, the shorter the lags, the more varieties are used in production and the higher $Z_{\tau}$ is.

The price index of technology- $\tau$ output is

$$
\begin{aligned}
p_{\tau} & =\left(\int_{\tau}^{t-D_{\tau}} p_{\tau, v}^{-\frac{1}{\mu-1}} d v\right)^{-(\mu-1)} \\
& =\frac{w^{1-\alpha}}{Z_{\tau}}(1-\alpha)^{-(1-\alpha)} \alpha^{-\alpha}
\end{aligned}
$$

Diffusion equation.- Combining the demand for sector $\tau$ output, (12), the sectoral price deflator (21), the expression for the equilibrium wage rate (14), the expression for $Z_{\tau},(20)$ and denoting logs with lower-case letters, we obtain

$$
y_{\tau}=y+\frac{\theta}{\theta-1}\left[z_{\tau}-(1-\alpha)(y-l)\right]
$$

From expression (20) we see that, to a first order approximation, $\gamma$ only affects $y_{\tau}$ through the linear trend. This allows us to do a second-order approximation of $\log Z_{\tau}$ around the starting adoption date as

$$
z_{\tau} \approx \ln a_{\tau}+(\chi+\gamma) \tau+(\mu-1) \ln \left(t-\tau-D_{\tau}\right)+\frac{\gamma}{2}\left(t-\tau-D_{\tau}\right)
$$

Substituting (23) in (22) gives us the following estimating equation ${ }^{14}$

\footnotetext{
${ }^{14}$ When bringing the model to the data, we shall see that some of the technology measures we have in our data set correspond to the output produced with a specific technology, and therefore equation (25) is the appropriate model counterpart. Other technology measures, instead, capture the number of units of the input that embody the technology (e.g. number of computers). The model counterpart to those measures is $X_{\tau}$. To derive an estimating equation for these measures, we integrate (15) across vintages to obtain (in logs) $x_{\tau}^{c}=y_{\tau}^{c}+p_{\tau}^{c}+\ln (\alpha)$. Substituting in for equation (25), we obtain an analogous expression to the one used in the main text,
}

$$
x_{\tau t}^{c}=\beta_{\tau 1}^{c}+y_{t}^{c}+\beta_{\tau 2} t+\beta_{\tau 3}\left((\mu-1) \ln \left(t-D_{\tau}^{c}-\tau\right)-(1-\alpha)\left(y_{t}^{c}-l_{t}^{c}\right)\right)+\varepsilon_{\tau t}^{c} .
$$




$$
y_{\tau t}^{c}=\beta_{\tau 1}^{c}+y_{t}^{c}+\beta_{\tau 2} t+\beta_{\tau 3}\left((\mu-1) \ln \left(t-D_{\tau}^{c}-\tau\right)-(1-\alpha)\left(y_{t}^{c}-l_{t}^{c}\right)\right)+\varepsilon_{\tau t}^{c},
$$

where $y_{\tau t}^{c}$ denotes the log of the output produced with technology $\tau, y_{t}^{c}$ is the $\log$ of output, $y_{t}^{c}-l_{t}^{c}$ is the log of output per capita, $\varepsilon_{\tau t}^{c}$ is an error term, and the country-technology specific intercept, $\beta_{1}^{c}$, is equal to

$$
\beta_{\tau 1}^{c}=\beta_{\tau 3}\left(\ln a_{\tau}^{c}+\left(\chi+\frac{\gamma}{2}\right) \tau-\frac{\gamma}{2} D_{\tau}^{c}\right)
$$

Equation (25) shows that the adoption lag $D_{\tau}^{c}$ is the only determinant of shifts in the curvature of the diffusion curve. Intuitively, longer lags imply that fewer vintages available for production and, because of the diminishing gains from variety, the steepness of the diffusion curve declines faster than if more vintages had been already adopted. Equation (26) shows that, for a given adoption lag, the only driver of cross-country differences in the intercept $\beta_{\tau 1}^{c}$ is the intensive margin, $a_{\tau}^{c}$. A lower level of $a_{\tau}^{c}$ generates a downward shift of the diffusion curve which, ceteris paribus, leads to lower output associated with technology $\tau$ throughout its diffusion and, in particular in the long-run. ${ }^{15}$

Formally, we can identify differences in the intensive margin relative to a benchmark, which we take to be the average value for 17 Western countries (defined by Maddison, 2004) ${ }^{16}$ as

$$
\ln a_{\tau}^{c}=\frac{\beta_{1, \tau}^{c}-\beta_{1, \tau}^{W e s t e r n}}{\beta_{3, \tau}}+\frac{\gamma}{2}\left(D_{\tau}^{c}-D_{\tau}^{W e s t e r n}\right) .
$$

\subsubsection{The intensive and extensive margin}

Estimation.- Comin and Hobijn (2010) and Comin and Mestieri (2010, 2013) develop a two step procedure to estimate (24) and (25). First, they estimate the equation jointly for a few countries for which the data series are longest and the data quality is highest. Here, we follow Comin and Mestieri (2013) and use the U.S., the UK and France. Then, imposing the estimates of $\hat{\beta}_{2 \tau}$ and $\hat{\beta}_{3 \tau}$, which are in principle common across countries, they re-estimate the equation to obtain the country-technology estimates of $D_{\tau}^{c}$ and $a_{\tau}^{c}$.

We focus on a sub-sample of 25 technologies that have a wider coverage over rich and poor countries and for which the data captures the initial phases of diffusion (see Appendix A). These technologies cover a wide range of sectors in the economy (transportation, communi-

\footnotetext{
${ }^{15}$ The intuition for why using a second order approximation of productivity growth suffices is that identification of adoption lags comes through the initial stages of diffusion, where the diffusion curve has more curvature than a log-linear trend (as when it becomes log-linear, it is impossible to separately identify it from embodied productivity growth). Hence, the approximation of the diffusion curve around the initial stages.

${ }^{16}$ These countries are Austria, Belgium, Denmark, Finland, France, Germany, Italy, Netherlands, Norway, Sweden, Switzerland, Untied Kingdom, Japan, Australia, New Zealand, Canada and the United States of America.
} 
cation and IT, industrial, agricultural and medical sectors). Their invention dates also span quite evenly over the last 200 years.

As in Comin and Hobijn (2010), we use the plausibility and precision of the estimates of the adoption lags from equation (25) as a pre-requisite to utilize the technology-country pair in our analysis. We find that these two conditions are met for the majority of the technology country-pairs (67\%). ${ }^{17}$ For these technology country-pairs, we find that equation (25) provides a very good fit for the data with an average detrended $R^{2}$ of 0.79 across countries and technologies (Table 11). ${ }^{18}$

Statistics.-Tables 3 and 4 report summary statistics for the estimates of the adoption lags and the intensive margin for each technology. The average adoption lag across all technologies (and countries) is 44 years. We find significant variation in average adoption lags across technologies. The range goes from 7 years for the Internet to 121 years for steam and motor ships. There is also considerable cross-country variation in adoption lags for any given technology. The range for the cross-country standard deviations goes from 3 years for PCs to 53 years for steam and motor ships.

We also find significant cross-country variation in the intensive margin. The intensive margin is reported as log differences relative to the average adoption of Western countries. ${ }^{19}$ The average intensive margin is -0.62 , which implies that the level of adoption of the average country is $54 \%$ of the Western countries. More generally, there is significant cross-country dispersion in the intensive margin. The range goes from 0.3 for mail to 1.1 for cars and the Internet. These summary statistics for the estimates of adoption lags and the intensive margin of adoption are consistent with those in Comin and Hobijn (2010) and Comin and Mestieri (2010) which use smaller technology samples and estimate other versions of the diffusion equation (25).

Evolution.- The long-time spans and cross-country coverage of the technologies in CHAT allow us to explore the presence of cross-country trends in adoption patterns. Comin and Hobijn (2010) explored whether there has been any trend in adoption lags over the last 200 years. They find that the average lag with which countries adopt technologies has dropped

\footnotetext{
${ }^{17}$ Plausible adoption lags are those with an estimated adoption date of no less than ten years before the invention date (this is to allow for some inference error). Precise are those with a significant estimate of adoption lags and the intercept $\beta_{1 \tau}^{c}$ at a $5 \%$ level. Following Comin and Hobijn (2010), we relax this condition and include in the "precise" category those estimates that have a standard error of adoption lags smaller than

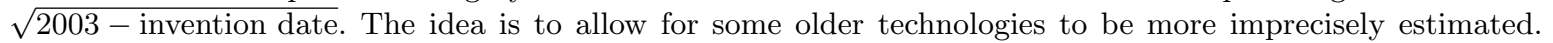
However, this additional margin hardly expands the set of precise estimates. Only 15 additional estimates are included with this condition, which represent $1.2 \%$ of our precise observations. Most of the implausible estimates correspond to diffusion curves that do not have the initial phases of diffusion. This makes it very hard to separately identify the log-linear trend from the log component of (25).

${ }^{18}$ To compute the detrended $R^{2}$, we partial out the linear trend $\gamma t$ and compute the $R^{2}$ of the detrended data.

${ }^{19}$ To compute the intensive margin we follow Comin and Mestieri (2013) and calibrate $\gamma=(1-\alpha) \cdot 1 \%$, $\alpha=0.3$, and use a value of $\beta_{3, \tau}$ that results from setting the elasticity across technologies $\theta$ to be the mean across our estimates, which is $\theta=1.28$.
} 
Table 3: Estimated Adoption Lags

\begin{tabular}{lcccccccc}
\hline \hline & Invention & & & & & & \\
& Year & Obs. & Mean & SD & P10 & P50 & P90 & IQR \\
\hline Spindles & 1779 & 31 & 119 & 48 & 51 & 111 & 171 & 89 \\
Steam and Motor Ships & 1788 & 45 & 121 & 53 & 50 & 128 & 180 & 104 \\
Railways Freight & 1825 & 46 & 74 & 34 & 31 & 74 & 123 & 50 \\
Railways Passengers & 1825 & 39 & 72 & 39 & 16 & 70 & 123 & 63 \\
Telegraph & 1835 & 43 & 45 & 32 & 10 & 40 & 93 & 43 \\
Mail & 1840 & 47 & 46 & 37 & 8 & 38 & 108 & 62 \\
Steel (Bessemer, Open Hearth) & 1855 & 41 & 64 & 34 & 14 & 67 & 105 & 51 \\
Telephone & 1876 & 55 & 50 & 31 & 8 & 51 & 88 & 51 \\
Electricity & 1882 & 82 & 48 & 23 & 15 & 53 & 71 & 38 \\
Cars & 1885 & 70 & 39 & 22 & 11 & 34 & 65 & 36 \\
Trucks & 1885 & 62 & 36 & 22 & 9 & 34 & 62 & 32 \\
Tractor & 1892 & 88 & 59 & 20 & 18 & 67 & 69 & 12 \\
Aviation Freight & 1903 & 43 & 40 & 15 & 26 & 42 & 60 & 19 \\
Aviation Passengers & 1903 & 44 & 28 & 16 & 9 & 25 & 52 & 18 \\
Electric Arc Furnace & 1907 & 53 & 50 & 19 & 27 & 55 & 71 & 34 \\
Fertilizer & 1910 & 89 & 46 & 10 & 35 & 48 & 54 & 7 \\
Harvester & 1912 & 70 & 38 & 18 & 10 & 41 & 54 & 17 \\
Synthetic Fiber & 1924 & 48 & 38 & 5 & 33 & 39 & 41 & 2 \\
Blast Oxygen Furnace & 1950 & 39 & 14 & 8 & 7 & 13 & 26 & 11 \\
Kidney Transplant & 1954 & 24 & 13 & 7 & 3 & 13 & 25 & 5 \\
Liver Transplant & 1963 & 21 & 18 & 6 & 14 & 18 & 24 & 3 \\
Heart Surgery & 1968 & 18 & 12 & 6 & 8 & 13 & 20 & 4 \\
Cellphones & 1973 & 82 & 13 & 5 & 9 & 14 & 17 & 6 \\
PCs & 1973 & 68 & 16 & 3 & 12 & 15 & 19 & 3 \\
Internet & 1983 & 58 & 7 & 4 & 1 & 7 & 11 & 3 \\
& & & & & & & & \\
All Technologies & & & & & & & & \\
\hline \hline & & 1306 & 44 & 35 & 9 & 38 & 86 & 46 \\
\hline
\end{tabular}

with the invention date of technologies. In particular, they find that technologies invented 10 years later, on average, have been adopted 4 years earlier (relative to the invention date).

The first column of Table 5 extends this finding to our 25 technologies. More specifically, it reports the estimates of regressing the (log) adoption lags on the invention date (minus 1820) and a constant. The first column reports the results from this regression for the whole sample. The constant term shows the average (log) adoption level in 1820 . The negative coefficient in the invention date illustrates the finding in Comin and Hobijn (2010) that new technologies have diffused on average faster.

Comin and Mestieri (2013) go one step further and ask whether the trend in adoption lags is uniform across countries. In particular, has it been the same for Western leaders and for non-Western followers? Column 2 of Table 5 reports the regression for Western countries 
Table 4: Estimated Intensive Margin

\begin{tabular}{lcccccccc}
\hline \hline & Invention & & & & & & & \\
& Year & Obs. & Mean & SD & P10 & P50 & P90 & IQR \\
\hline Spindles & 1779 & 31 & -0.02 & 0.6 & -0.8 & -0.1 & 0.8 & 0.7 \\
Steam and Motor Ships & 1788 & 45 & -0.01 & 0.6 & -0.6 & 0.0 & 0.7 & 0.6 \\
Railways Freight & 1825 & 46 & -0.17 & 0.4 & -0.6 & -0.2 & 0.4 & 0.6 \\
Railways Passengers & 1825 & 39 & -0.24 & 0.5 & -0.9 & -0.2 & 0.2 & 0.5 \\
Telegraph & 1835 & 43 & -0.26 & 0.5 & -1.0 & -0.2 & 0.3 & 0.7 \\
Mail & 1840 & 47 & -0.19 & 0.3 & -0.6 & -0.1 & 0.1 & 0.4 \\
Steel (Bessemer, Open Hearth) & 1855 & 41 & -0.22 & 0.4 & -0.7 & -0.1 & 0.2 & 0.6 \\
Telephone & 1876 & 55 & -0.91 & 0.9 & -2.2 & -0.8 & 0.1 & 1.2 \\
Electricity & 1882 & 82 & -0.58 & 0.6 & -1.2 & -0.5 & 0.1 & 0.9 \\
Cars & 1885 & 70 & -1.13 & 1.1 & -2.1 & -1.1 & 0.1 & 1.6 \\
Trucks & 1885 & 62 & -0.86 & 1.0 & -1.7 & -0.8 & 0.1 & 1.1 \\
Tractor & 1892 & 88 & -1.02 & 0.9 & -2.3 & -0.9 & 0.1 & 1.5 \\
Aviation Freight & 1903 & 43 & -0.39 & 0.6 & -1.3 & -0.2 & 0.2 & 0.9 \\
Aviation Passengers & 1903 & 44 & -0.45 & 0.7 & -1.3 & -0.4 & 0.2 & 0.9 \\
Electric Arc Furnace & 1907 & 53 & -0.29 & 0.5 & -0.9 & -0.2 & 0.3 & 0.8 \\
Fertilizer & 1910 & 89 & -0.83 & 0.8 & -1.9 & -0.7 & 0.1 & 1.3 \\
Harvester & 1912 & 70 & -1.10 & 1.0 & -2.7 & -1.0 & 0.2 & 1.5 \\
Synthetic Fiber & 1924 & 48 & -0.52 & 0.7 & -1.6 & -0.4 & 0.2 & 0.9 \\
Blast Oxygen Furnace & 1950 & 39 & -0.81 & 0.9 & -2.3 & -0.4 & 0.1 & 1.8 \\
Kidney Transplant & 1954 & 24 & -0.19 & 0.4 & -0.8 & -0.1 & 0.1 & 0.3 \\
Liver Transplant & 1963 & 21 & -0.33 & 0.7 & -1.6 & -0.1 & 0.1 & 0.5 \\
Heart Surgery & 1968 & 18 & -0.44 & 0.8 & -1.7 & -0.1 & 0.2 & 0.6 \\
Cellphones & 1973 & 82 & -0.75 & 0.7 & -1.8 & -0.6 & 0.1 & 1.2 \\
PCs & 1973 & 68 & -0.60 & 0.6 & -1.4 & -0.6 & 0.1 & 0.9 \\
Internet & 1983 & 58 & -0.96 & 1.1 & -2.1 & -0.8 & 0.1 & 1.5 \\
& & & & & & & & \\
All Technologies & & 1306 & -0.62 & 0.8 & -1.7 & -0.4 & 0.2 & 1.0 \\
\hline \hline & & & & & & & & \\
\hline
\end{tabular}

and column 3 for non-Western countries. In 1820, adoption lags were significantly shorter in Western countries than in non-Western countries. However, the rate of decline of adoption lags has been significantly larger in non-Western countries than in Western countries $(1.12 \%$ vs. $0.81 \%$ ). Therefore, adoption lags have converged across countries. ${ }^{20}$

We conduct a similar exercise for the intensive margin of adoption. Given that the intensive margin is defined relative to a benchmark, the evolution of the average intensive margin is not very meaningful, but we can still ask the question of whether there has been convergence in the intensive margin across countries. Comin and Mestieri (2013) explore this question by regressing the intensive margin on the invention date of the technology (minus 1820) and a

\footnotetext{
${ }^{20}$ Comin and Mestieri (2013) show that this finding extends to considering alternative country groupings such as bottom $10 \%$ and $20 \%$ of countries according to their income.
} 
Table 5: Evolution of the Adoption Lag

\begin{tabular}{|c|c|c|c|}
\hline Dependent Variable is: & $\begin{array}{c}(1) \\
\log (\operatorname{Lag}) \\
\text { World } \\
\end{array}$ & $\begin{array}{c}(2) \\
\log (\operatorname{Lag}) \\
\text { Western Countries }\end{array}$ & $\begin{array}{c}(3) \\
\log (\operatorname{Lag}) \\
\text { Rest of the World }\end{array}$ \\
\hline Year-1820 & $\begin{array}{l}-0.0106^{*} \\
(0.0004)\end{array}$ & $\begin{array}{l}-0.0081^{*} \\
(0.0006)\end{array}$ & $\begin{array}{l}-0.0112^{*} \\
(0.0004)\end{array}$ \\
\hline Constant & $\begin{array}{c}4.27^{*} \\
(0.06)\end{array}$ & $\begin{array}{c}3.67^{*} \\
(0.07)\end{array}$ & $\begin{array}{l}4.48^{*} \\
(0.05)\end{array}$ \\
\hline $\begin{array}{l}\text { Observations } \\
\text { R-squared }\end{array}$ & $\begin{array}{l}1274 \\
0.45\end{array}$ & $\begin{array}{r}336 \\
0.34\end{array}$ & $\begin{array}{r}938 \\
0.53\end{array}$ \\
\hline
\end{tabular}

Note: robust standard errors in parentheses, ${ }^{*}$ denotes $1 \%$ significance. Each observation is re-weighted so that each technology carries equal weight.

Table 6: Evolution of the Intensive Margin

\begin{tabular}{lccc}
\hline \hline Dependent Variable is: & $\begin{array}{c}(1) \\
\text { Intensive } \\
\text { World }\end{array}$ & $\begin{array}{c}(2) \\
\text { Intensive } \\
\text { Western Countries }\end{array}$ & $\begin{array}{c}(3) \\
\text { Intensive } \\
\text { Rest of the World }\end{array}$ \\
\hline Year-1820 & $-0.0029^{*}$ & 0.0000 & $-0.0054^{*}$ \\
& $(0.0005)$ & $(0.0002)$ & $(0.0005)$ \\
Constant & $-0.32^{*}$ & -0.00 & $-0.39^{*}$ \\
& $(0.05)$ & $(0.06)$ & $(0.07)$ \\
Observations & & & \\
R-squared & 1306 & 350 & 956 \\
\hline \hline
\end{tabular}

Note: robust standard errors in parentheses, ${ }^{*}$ denotes $1 \%$ significance. Each observation is re-weighted so that each technology carries equal weight. 
constant. Table 6 reports their main finding. As shown in column 3, the intensive margin in non-Western countries (relative to the Western average) has declined (with the invention date) at a rate of $0.54 \%$ per year. This estimate implies that the gap in the intensity of technology adoption between rich and poor countries is larger for newer than for old technologies. So, there has been divergence in the intensive margin over the last 200 years. In Section (4.3) we review the implications that this has had on the cross-country dynamics of income.

Robustness checks.- One important identification assumption is that the curvature of the diffusion curve $(25), \beta_{3 \tau}$, is common across countries for a given technology $\tau$. Comin and Hobijn (2010) evaluate this hypothesis by allowing it to vary by technology country pair and then testing the null that the common and the country-specific estimate of $\beta_{3 \tau}$ are the same. Reassuringly, they find that they cannot reject the null that both estimates are the same for $69 \%$ of the technology-country pairs.

A second restriction used in the estimation -this one imposed by the model - is that the elasticity of technology with respect to income is one. The homotheticity of technology may be a restrictive constraint in reality. To evaluate the robustness of the findings to alternative formulations of the demand for technology, Comin and Mestieri (2013) propose a method to estimate the income elasticity of technology. Specifically, they estimate the income elasticity of technology in the first stage (along with $\beta_{2}$ and $\beta_{3}$ ) for the three baseline countries (U.S., UK and France). Effectively, this implies that the income elasticity of technology is identified from the time-series variation of technology and income for these countries. Since the time-span of the diffusion for most technologies in these countries is quite long, it covers periods when their income was far lower than today. Hence, this estimate seems a reasonable proxy for the income elasticity of technology in developing countries too. They find that both the estimates and the trends in adoption described above are robust to allowing for non-homotheticities in demand.

\subsection{Other Approaches}

We conclude our discussion of the measurement of technology by mentioning one recent approach proposed by Alexopoulos (2011). Her approach consists in measuring technology by the number of books published in the field of a particular technology. The rationale of this measure is that technology books are published when new discoveries (relevant for the industry) are made. One advantage of this measure is that, because the topics covered by books are classified into narrow fields, it is possible to collect time-series measures for relatively disaggregated fields.

One important question is whether these measures capture innovations or diffusion of the innovations. To explore this issue, Alexopoulos shows that the number of new books

on a given technological field peak in the early stages of diffusion of a new technology, and 
lead other measures of diffusion of the technology. She argues based on this evidence that books measure innovation rather than diffusion. However, Alexopoulos also shows that both R\&D expenditures and patent applications lead the number of science books published. This would suggest that the number of technology books published in a discipline does not reflect innovation but measure technology some time after the innovation has taken place. One plausible hypothesis is that the number of books published reflect the expected value of the technology at the early stages of diffusion, which is when it may be optimal to publish a book.

\section{Drivers of Technology Adoption}

After showing the magnitude of the existing cross-country differences in technology, one can only wonder about what factors explain the large cross-country differences in technology. At this point, it may be safe to conjecture that there may be a large number of factors that drive cross-country differences in technology. Many of them may still be unexplored, while we are just beginning to have direct evidence of the relevance of a few others.

As before, in this section, we will tend to focus on studies that have explored cross-country differences in technology as opposed to within country differences. In part, because it is not clear that the drivers of adoption within country are the same as those across countries. However, when relevant, we describe within country evidence. As in Section 2, we also prioritize studies that consider direct measures of multiple technologies because of our interest in uncovering general patterns in the data.

We organize our exposition by classifying the drivers into three broad categories. The first two (knowledge, and institutions/policies) affect technology from the supply side, while the third (aggregate demand) represents the pull forces of technology. ${ }^{21}$

\subsection{Knowledge}

New technology brings new production processes, machines, products and services which typically are not straightforward to implement (Comin and Hobijn, 2007). A significant part of the cost of adopting new technologies is the cost of figuring out what technology is needed to produce the desired good or service and how to use it individually or as part of an existing production process. Therefore, any prior knowledge that reduces the magnitude of these costs should foster technology adoption.

Knowledge may take a variety of forms depending on who has it, and its nature. Nelson and Phelps (1966) focused on human capital; that is, formal knowledge embodied in people. ${ }^{22}$ Human capital has typically been measured as the fraction of population that has attained

\footnotetext{
${ }^{21}$ As we show below, both profitability and spread of information - the traditional drivers of adoption for the economics and marketing literatures - are comprised in these categories.

${ }^{22}$ See Benhabib and Spiegel (2005) for a more comprehensive survey of work exploring this hypothesis.
} 
a certain schooling level or as the fraction of population in schooling age that is enrolled in certain schooling level. Formal schooling may not be the only (or even the most relevant) source of knowledge for the adoption of new technologies since workers may learn on the job. ${ }^{23}$

In addition to knowledge embodied in people, knowledge may be collectively embodied in organizations or in sectors. The concept of organizational knowledge captures the notion that there may be complementarities between the knowledge of workers which increase the organization capacity to adopt new technologies beyond the sum of the workers individual capacities. Finally, a company's capabilities to adopt or use a new technology may be positively affected by the capabilities of other agents. These may be similar companies in the same geography (clusters), e.g., Porter (1998), or distinct organizations with which it interacts directly or indirectly. For example, a company may seek technological advice from public organizations that have prior experience in the technology (e.g., Fraunhofer in Germany, Comin et al., 2012). Finally, a company's adoption potential may be affected by the technological experience of companies in other geographies with which it has some contact. This implication would follow from a simple extension of epidemic diffusion models (to allow for multiple geographies).

Next, we review some evidence about the role of the different sources of knowledge on technology adoption.

\subsubsection{Human capital}

Caselli and Coleman (2001) explore the role of human capital in the diffusion of computers. Using data on the value of computer imports for 90 countries between 1970 and 1990, they study whether imports are affected by various measures of human capital. In their specification, they control for per-capita income, year-dummies, continent dummies and a country-level random effect. They find that an increase by one percentage point in the fraction of the population with more than primary schooling is associated with an increase in the value of computers imported by one percent.

Riddell and Song (2012) use Canadian micro-level data from the Workplace and Employee Survey to explore the same question. More specifically, these authors use time and state variation in compulsory education laws to instrument the education attainment of workers. Their main findings are that graduating from high-school increases the probability of using a computer in the job by 37 percentage points. Similarly, an additional year of schooling increases this probability by 7 percentage points. In contrast, they do not find any significant effect of education on the probability that a worker uses computer-controlled machines. There are a few remarks worth making about the findings in Riddell and Song (2012). First, the fact that a worker's own human capital does not affect his probability of adopting numerically controlled machines does not imply that human capital is irrelevant for the diffusion of this

\footnotetext{
${ }^{23}$ See for example Seshadri and Manuelli (2005), Erosa et al. (2010) and the references therein.
} 
technology. It may well be the case that the human capital of other relevant agents is important (technicians, managers, importers,... ). A second remark made by Riddell and Song concerns the significantly higher estimates (almost three times) for the effect of human capital on computer adoption when instrumenting education than with OLS. This result suggests that, with the instrumentation, the authors are probably capturing the local average treatment effect (LATE) rather than the average treatment effect (ATE) which is the relevant measure for the question posed.

One would like to explore whether the importance of human capital for technology adoption extends beyond computers. Benhabib and Spiegel (1994) find evidence that the stock of human capital affects the growth rate of productivity (i.e., TFP) which they interpret in the light of the Nelson and Phelps (1966) model. Comin and Hobijn (2004) look at the predecessor of CHAT (the HCCTAD) which contains information on the diffusion of 25 major technologies in 15 advanced countries over the last 200 years.

The specification used by Comin and Hobijn (2004) is similar to the one used by Caselli and Coleman (2001). In particular, they consider the following regression:

$$
y_{j t}^{c}=\eta_{j t}+\beta X_{j t}^{c}+\epsilon_{j t}^{c}
$$

where $y_{j t}^{c}$ denotes the adoption level of technology $j$ in country $c$ in year $t, \eta_{j t}$ is a full set of technology-time dummies, and $X_{j t}^{c}$ is a matrix of (possibly technology specific) controls. In particular $X_{j t}^{c}$ always include the log of GDP per capita and may include controls for the openness of the country, quality of political institutions, measures of adoption of general technologies (i.e., electricity) and of predecessor technologies. The regression results are reported in Table 7.

Because of data constraints, Comin and Hobijn (2004) allow for different effects of enrollment rates before and after 1970 . The most robust result they find concerning human capital is that, until 1970, secondary enrollment is positively associated with technology adoption. This effect does not diminish after including all these controls with the exception of electricity production and the predecessor technologies which reduces significantly the sample (from over 5000 to 1000 observations) and reduces the regression coefficient by a fourth (from 0.3 to 0.22 ). After 1970, however, they find no significant effect of secondary enrollment on technology adoption. Attainment rates (in all schooling level) are also positively associated with technology adoption.

Comin and Hobijn (2004) also explore the association between education and adoption of specific technologies. Consistent with Riddell and Song (2012), they find heterogeneity in the coefficients. The positive impact of secondary schooling on adoption is driven by mass communication technologies (newspapers, radio and TV) and by electricity. For the other technologies the association with secondary enrollment is insignificant. For transportation 
Table 7: Technology Pooled Regressions

\begin{tabular}{|c|c|c|c|c|c|c|c|c|c|}
\hline \multirow[b]{2}{*}{$\ln (\mathrm{RGDPpc})$} & \multicolumn{9}{|c|}{ Dependent Variable is: Technology $y_{c j t}$} \\
\hline & $\begin{array}{r}1.15 \\
(0.03)^{*}\end{array}$ & $\begin{array}{r}1.12 \\
(0.03)^{*}\end{array}$ & $\begin{array}{r}0.57 \\
0(0.07)^{*}\end{array}$ & $\begin{array}{r}1.10 \\
(0.03)^{*}\end{array}$ & $\begin{array}{r}1.05 \\
(0.04)^{*}\end{array}$ & $\begin{array}{r}0.93 \\
(0.05)^{*}\end{array}$ & $\begin{array}{r}1.04 \\
(0.35)^{*}\end{array}$ & $\begin{array}{r}1.04 \\
(0.03)^{*}\end{array}$ & $\begin{array}{r}1.2 \\
(0.09)^{*}\end{array}$ \\
\hline Prim.enr. 70- & & $\begin{array}{r}0.09 \\
(0.06)\end{array}$ & & $\begin{array}{r}0.06 \\
(0.07)\end{array}$ & $\begin{array}{r}0.08 \\
(0.07)\end{array}$ & $\begin{array}{r}1.23 \\
(0.18)^{*}\end{array}$ & $\begin{array}{r}0.10 \\
(0.07)\end{array}$ & $\begin{array}{r}0.09 \\
(0.07)\end{array}$ & $\begin{array}{r}1.69 \\
(0.26)^{*}\end{array}$ \\
\hline Prim enr. $70+$ & & $\begin{array}{r}0.35 \\
(0.21)\end{array}$ & & $\begin{array}{r}0.39 \\
(0.23)\end{array}$ & $\begin{array}{r}0.22 \\
(0.23)\end{array}$ & $\begin{array}{r}-0.11 \\
(0.2)\end{array}$ & & & $\begin{array}{r}-0.48 \\
(0.4)\end{array}$ \\
\hline Sec.enr. 70- & & $\begin{array}{r}0.30 \\
(0.08)^{*}\end{array}$ & & $\begin{array}{r}0.36 \\
(0.08)^{*}\end{array}$ & $\begin{array}{r}0.31 \\
(0.08)^{*}\end{array}$ & $\begin{array}{r}0.37 \\
(0.09)^{*}\end{array}$ & $\begin{array}{r}0.27 \\
(0.08)^{*}\end{array}$ & $\begin{array}{r}0.3 \\
(0.08)^{*}\end{array}$ & $\begin{array}{r}0.22 \\
(0.12)\end{array}$ \\
\hline Sec.enr $70+$ & & $\begin{array}{r}0.08 \\
(0.128)\end{array}$ & & $\begin{array}{r}0.05 \\
(0.15)\end{array}$ & $\begin{array}{r}-0.01 \\
(0.15)\end{array}$ & $\begin{array}{r}0.13 \\
(0.27)\end{array}$ & & & $\begin{array}{r}-0.36 \\
(0.36)\end{array}$ \\
\hline $\begin{array}{l}\text { Prim.Att. } \\
\text { Prim.Att. } \\
\text { Sec.Att }\end{array}$ & & & $\begin{array}{r}0.01 \\
(0.00)^{*} \\
0.01 \\
(0.00)^{*}\end{array}$ & & & & & & \\
\hline Tert.Att & & & $\begin{array}{r}0.01 \\
(0.00)^{*}\end{array}$ & & & & & & \\
\hline Openness & & & & $\begin{array}{r}0.06 \\
(0.02)^{*}\end{array}$ & $\begin{array}{r}0.06 \\
(0.02)^{*}\end{array}$ & $\begin{array}{r}0.24 \\
(0.11)\end{array}$ & $\begin{array}{r}0.07 \\
(0.02)^{*}\end{array}$ & $\begin{array}{r}0.31 \\
(0.09)^{*}\end{array}$ & $\begin{array}{r}0.35 \\
(0.15)^{*}\end{array}$ \\
\hline TwtGDP & & & & & & & $\begin{array}{r}-0.22 \\
(0.06)^{*}\end{array}$ & & \\
\hline Open. · TwtGDP & & & & & & & & $\begin{array}{r}-0.15 \\
(0.05)^{*}\end{array}$ & \\
\hline Ex.mon. & & & & & $\begin{array}{r}0.16 \\
(0.07)\end{array}$ & & $\begin{array}{r}0.13 \\
(0.07)\end{array}$ & $\begin{array}{r}0.14 \\
(0.07)\end{array}$ & \\
\hline Ex.prem. & & & & & $\begin{array}{r}-0.11 \\
(0.04)\end{array}$ & $\begin{array}{r}0.06 \\
(0.06)\end{array}$ & $\begin{array}{r}-0.14 \\
(0.04)^{*}\end{array}$ & $\begin{array}{r}-0.12 \\
(0.04)^{*}\end{array}$ & $\begin{array}{r}-0.05 \\
(0.08)\end{array}$ \\
\hline Ex.Other & & & & & $\begin{array}{r}-0.33 \\
(0.06)^{*}\end{array}$ & $\begin{array}{r}-0.17 \\
(0.08)\end{array}$ & $\begin{array}{r}-0.36 \\
(0.06)^{*}\end{array}$ & $\begin{array}{r}-0.33 \\
(0.06)^{*}\end{array}$ & $\begin{array}{r}-0.53 \\
(0.11)^{*}\end{array}$ \\
\hline Mil.Reg. & & & & & $\begin{array}{r}-0.42 \\
(0.08)^{*}\end{array}$ & $\begin{array}{r}-0.46 \\
(0.15)^{*}\end{array}$ & $\begin{array}{r}-0.45 \\
(0.08)^{*}\end{array}$ & $\begin{array}{r}-0.43 \\
(0.08)^{*}\end{array}$ & $\begin{array}{r}-1.17 \\
(0.19)\end{array}$ \\
\hline Legislat. Eff. & & & & & & $\begin{array}{r}-0.16 \\
(0.05)^{*}\end{array}$ & & & $\begin{array}{r}-0.31 \\
(0.07)^{*}\end{array}$ \\
\hline Party & & & & & & $\begin{array}{r}0.08 \\
(0.04)\end{array}$ & & & $\begin{array}{r}0.75 \\
(0.05)\end{array}$ \\
\hline $\ln (\mathrm{MWHR})$ & & & & & & & & & $\begin{array}{r}0.06 \\
(0.04)^{*}\end{array}$ \\
\hline Prev.tech & & & & & & & & & $\begin{array}{r}0.16 \\
(0.03)^{*}\end{array}$ \\
\hline No. of obs. & 5488 & 5417 & 2341 & 4986 & 4986 & 2118 & 5057 & 5057 & 1000 \\
\hline$R^{2}$ (within) & 0.24 & 0.24 & 0.17 & 0.23 & 0.25 & 0.33 & 0.25 & 0.24 & 0.48 \\
\hline
\end{tabular}

Notes: Standard errors in parentheses, ${ }^{*}$ denotes significance at $1 \%$ level. The technology measures included from CHAT are: Fraction of spindles that are ring spindles, Fraction of tonnage of steel produced using Bessemer method, Fraction of tonnage of steel produced using Open Hearth furnaces, Fraction of tonnage of steel produced using Blast Oxygen furnaces, Fraction of tonnage of steel produced using Electric Arc furnaces, Mail per capita, Telegrams per capita, Telephones per capita, Mobile phones per capita, Newspapers per capita, Radios per capita, Televisions per capita, Personal computers per capita, Industrial robots per unit of real GDP, Freight traffic on railways (TKMs) per unit of real GDP, Passenger traffic on railways (PKMs) per capita, Trucks per unit of GDP, Passenger cars per capita, Aviation cargo (TKMs) per unit of real GDP, Aviation passengers (PKMs) per capita, Transportation (shipping), Fraction of merchant fleet (tonnage) made up of steamships and motorships, MWhr of electricity produced per unit of real GDP. TwtGDP and Previous technology have been instrumented for 5 year lagged values. 
technologies they find a positive association between primary enrollment and technology diffusion; and a negative one for steel production technologies. Finally, and consistent with the previous evidence, they find a positive and significant association between the rate of tertiary attainment and the adoption of computers.

\subsubsection{Adoption history}

Vintage capital models, either based on human or physical capital (e.g., Johansen, 1959, Solow, 1960, Chari and Hopenhayn, 1991 and Caselli, 1999) predict some form of leapfrogging because of the difficulty to transfer technology-specific human or physical capital from old to new technologies. Comin and Hobijn (2004) test this prediction by matching technologies in HCCTAD to their predecessor technologies. In particular, they use information on the diffusion of 11 technologies for which they have information for both new and predecessor technologies. Contrary to the vintage capital models, they find that there is a positive association between the adoption of predecessor and new technologies. This effect is robust to controlling for variables that affect the overall return to adopting new technologies in the country such as income, education, trade openness, and the institutional environment. ${ }^{24}$

This finding suggests that there are inputs in the adoption process that are transferable across technologies within a sector. These inputs are not formal human capital since this is one of the controls. They do not capture institutional quality, openness or other variables that are likely to have a symmetric effect across technologies since income is also in the set of controls. What can they capture then?

Comin et al. (2010)'s investigation shed some light on this question. Combining the data set on country-level measures of historical technology adoption described in Section 2.1 and measures of adoption for current times from CHAT, Comin et al. (2010) explore the effect of historical adoption on current adoption. This exercise is distinct from Comin and Hobijn (2004) in at least two respects. First, it covers all countries, not just 15 rich countries. Second, the periods they considered are 1000 BC, 0AD, 1500 AD and 2000 AD. Therefore, the horizons over which they estimate the persistence of technology adoption are much longer than in Comin and Hobijn (2004).

Figure 3 presents one of the key findings. The overall technology adoption level in 1500 A.D. is positively and significantly associated with current income per capita. This $R^{2}$ indicates that this measure of technology in 1500 A.D. accounts for 18 percent of the variation in log per capita GDP in 2002. Changing from the maximum (i.e. 1) to the minimum (i.e. 0) the overall technology adoption level in 1500 A.D. is associated with a reduction in the level of income per capita in 2002 by a factor of 5 . The authors also find a similar association between

\footnotetext{
${ }^{24}$ For steel production technologies, they find a negative partial association between the adoption of new and predecessor technologies.
} 
Figure 3: Technology in $1500 \mathrm{AD}$ and current development

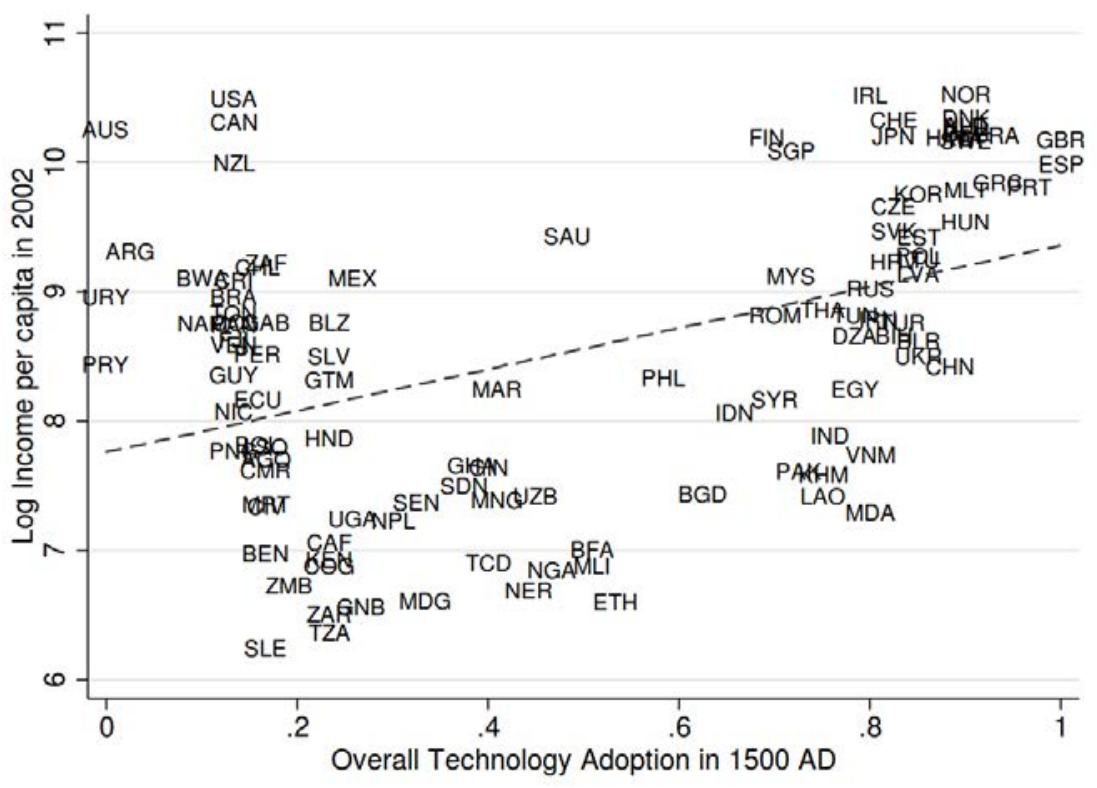

past and current technologies. The association is robust to including continent dummies, and controlling for geographical variables.

This persistence of technology adoption may well be the result of some persistent factor that affects (contemporaneously) technology adoption. The literature has suggested a few, such as genetic endowment (Ashraf and Galor, 2013, Spolaore and Wacziarg, 2009), culture (Tabellini, 2007; and Guiso et al., 2008) and institutions (Acemoglu et al., 2002 and Bockstette et al., 2002). Comin et al. (2010) note that these factors are likely to have a symmetric effect in technology adoption across sectors. In contrast, sector-specific knowledge is likely to have a larger effect on subsequent adoption within a given sector than in other sectors. This variation provides a natural identification strategy for the source of the persistence in technology adoption. In particular, one could compare the persistence in technology adoption at the sector level before and after including country time-varying effects. If the inclusion of country effects (which is equivalent to looking at deviations in adoption from the country mean in each period) does not affect dramatically the estimated persistence, we can conclude that it is unlikely to result from country-wide factors that affect symmetrically technology adoption across sectors.

Table 8 presents the results from this exercise. ${ }^{25}$ In it, we can see that including countrylevel effects does not change much the persistence of technology at the sector level. The point estimate declines from 0.4 to 0.29 and both are significant at the $1 \%$ level (see columns 1

\footnotetext{
${ }^{25}$ The specification used in Comin et al. (2010) allows for country-sector fixed effects in the level of adoption. They instrument the change in adoption with the lag level of adoption following Arellano and Bond (1991).
} 
Table 8: Persistence of Technology Within Countries

\begin{tabular}{|c|c|c|c|c|c|c|}
\hline & \multicolumn{6}{|c|}{ Dependent Variable: Technology ${ }_{c s t}$} \\
\hline & (1) & (2) & (3) & $(4)$ & $(5)$ & $(6)$ \\
\hline Technology $\mathrm{y}_{c s t-1}$ & $\begin{array}{r}0.4^{*} \\
(4.85)\end{array}$ & $\begin{array}{c}0.29^{*} \\
(4.84)\end{array}$ & $\begin{array}{c}0.25^{*} \\
(3.71)\end{array}$ & $\begin{array}{c}0.25^{*} \\
(3.11)\end{array}$ & $\begin{array}{r}0.39^{*} \\
(4.54)\end{array}$ & $\begin{array}{c}0.28^{*} \\
(4.12)\end{array}$ \\
\hline $\begin{array}{l}\text { Country-time } \\
\text { fixed effects }\end{array}$ & NO & YES & YES & YES & YES & YES \\
\hline $\begin{array}{l}\text { Sectors excluded } \\
\text { other than military }\end{array}$ & - & - & Agri. & Comm & Transp. & Indust. \\
\hline$N$ & 417 & 417 & 315 & 307 & 312 & 317 \\
\hline$R^{2}$ & - & 0.48 & 0.43 & 0.56 & 0.32 & 0.56 \\
\hline
\end{tabular}

Notes: t-statistics in parenthesis, ${ }^{*}$ denotes significance at $1 \%$. Panel regressions using (migration adjusted) technology level $a$ in sector $s$, country $c$ in year $t, a_{c s t}=\beta_{c s}+\beta_{c t}+\beta_{s} \cdot t+$ $\gamma \cdot a_{c s t-1}+\varepsilon_{c s t}$, where $\beta_{c s}$ is a country-sector fixed effect, $\beta_{c t}$ is a country-time fixed effect, $\beta_{s}$ is a technology specific trend and $\varepsilon_{c s t}$ is an error term. Regressions are estimated in first differences instrumenting $a_{c s t}-a_{c s t-1}$ with $a_{c s t-2}$ to avoid lagged dependent variable bias, where $t=2000, t-1=1500 A D, t-2=0$.

and 2). Furthermore, the results are not driven by the persistence of adoption in any single sector, as results in columns (3) to (6) show. These results suggest that the most likely driver of persistence in technology is the learning of sector-specific technological knowledge, which follows from adopting and using new technologies. Comin et al. (2010) further note that these dynamics are very pervasive and, based on their findings, can lead to large income differences across countries.

\subsubsection{Geographic interactions}

Most empirical studies on technology adoption have treated adoption units as independent. Consequently, they have tried to link a country's technology adoption patterns to the country's characteristics (e.g. human capital, institutions, policies, adoption history, etc.). This empirical approach to the drivers of technology adoption ignores the possibility of crosscountry interactions in the adoption process. This assumption might be restrictive. Adopting a technology requires acquiring knowledge which often comes from interactions with other agents. The frequency and success of these interactions is likely to be shaped by geography. Technological knowledge is likely to be more easily transmitted between agents in countries that are close than between agents located far apart. Similarly, the payoff to adopting a given technology (e.g. railways) may be affected by the adoption experience of neighboring countries. As argued in Diamond (1999), some technologies may be geography-specific. All these mechanisms may generate correlated adoption patterns across nearby countries. 
In the development literature, several studies have explored how the neighbors' adoption decision affect and agent's own decision. Foster and Rosenzweig (1995) study the adoption of high-yield varieties in Indian villages. They find that the profitability of this technology was increasing and concave in the neighbors' experience with the seeds. Bandiera and Rasul (2006) study the diffusion of sunflowers in Mozambique finding positive effects of neighbors adoption decisions on a farmer's adoption when few neighbors have adopted, but negative when a significant number of neighbors has. Conley and Udry (2010) study the fertilizer behavior of pineapple farmers in Ghana. They observe that a farmer will tend to imitate neighbors' fertilizer behavior when the neighbor has been successful in the past. This effect is stronger when the farmer has little experience of his own. ${ }^{26}$

Despite its importance, it is still difficult to ascertain the generality of the findings from existing micro studies. In particular, are informational frictions and social interactions relevant for other technologies (e.g. in other sectors, more complex, or more capital intensive)? And how relevant are informational frictions and interactions once the focus moves from explaining adoption differences among individuals to cross-country differences?

To explore the empirical importance of these mechanisms, Comin et al. (2013) (CDR, henceforth) measure how far a country is from the high-density points in the distribution of technology adoption in the other countries. They denote this measure of the spatial distance from other country's technology SDT. A negative correlation between SDT and adoption, after controlling for country and time fixed effects, implies that countries that are further away from those where the technology diffuses faster tend to experience a slower adoption of the technology.

Using data on twenty technologies from CHAT, they find a strong and significant negative partial correlation between SDT and a country's adoption. The estimates imply that spatial interactions that facilitate technology adoption decline by $73 \%$ every $1000 \mathrm{Kms}$. The estimates are robust to controlling for income, human capital, trade openness, institutions and for the spatial distance from other countries per-capita income (SDI), constructed in a way parallel to SDT.

To further explore the nature of the interactions that is causing the effect, CDR also explore whether the effect of other countries' technology evolves as the technology diffuses. Note that, interactions mediated by the flow of people or of goods and services would tend to persist over time. In contrast, interactions driven by the diffusion of knowledge should tend to vanish over time as knowledge is easier to replicate within one location. Consistent with this later hypothesis, CDR find that the effect of SDT on technology adoption diminishes as the diffusion process unfolds.

A final question CDR take on is Jared Diamond's hypothesis that technologies diffuse

\footnotetext{
${ }^{26}$ Similar neighbor effects have been observed in bed nets Dupas (2009). See Foster and Rosenzweig (2010) for a survey of the development literature.
} 
along latitudes. To explore this, they decompose SDT between two components one based on distances along latitudes and another based on distances along longitudes. Consistent with Diamond (1999), they find that latitude component of SDT has a stronger association with technology adoption than longitude component of SDT, although both have a significant effect. This finding is remarkable since their sample does not include any technology where climatic reasons might suggest that distance across latitudes is a larger impediment for diffusion than distance across longitudes.

One last form of geographic interaction considered in the literature is migration flows. International migration may have brought significant technological knowledge from areas with more advanced technologies to others where advanced technologies were rare. If that is the case, one would expect that adjusting knowledge flows by the movement of people should provide a more accurate account of the cross-country dynamics of productivity. With this idea in mind, Putterman and Weil (2010) explore whether the history of people matters more than history of places by measuring, for each country, the origin of the ancestors of today's population, going back to 1500AD. Putterman and Weil show that, after adjusting for historical migration flows, variables such as the antiquity of states and years of experience with agriculture have a greater explanatory power of current development. Comin et al. (2010) extend Putterman and Weil's analysis by applying the Putterman-Weil migration matrix to the historical technology adoption in 1500AD. This yields a measure of the historical adoption level in 1500AD of the ancestors to the people that live today in each country. With this migration-adjusted measures of technology, they re-examine their exploration of the persistence of technology adoption.

Figure 4 shows the simple scatter plot between migration-adjusted technological heritage from 1500 A.D. and per capita income today. Comparing Figure 4 with Figure 3, it is clear that long-run technological persistence is stronger overall if we base technology on peoples rather than places (the R-squared increases from .18 to .50). A movement from 0 to 1 is associated with an increase in per capita income today by a factor of 26.1! Similarly, this regression implies that 78 percent of the log difference in income today between sub-Saharan Africa and Western Europe is associated with the technology differences in 1500 A.D. Based on this evidence, it is clear that the propagation of technological knowledge through migration flows is an important source of cross-country differences in technology adoption.

\subsection{Institutions and policies}

In the same way that insufficient technological knowledge constrains the agents' ability to use a new technology in a productive way, inadequate political institutions may reduce the agents' incentive to incur in the costs of using a new technology. There is no lack of theoretical arguments and anecdotal evidence that point to specific mechanisms by which inadequate 
Figure 4: Migration-adjusted technology in $1500 \mathrm{AD}$ and current development

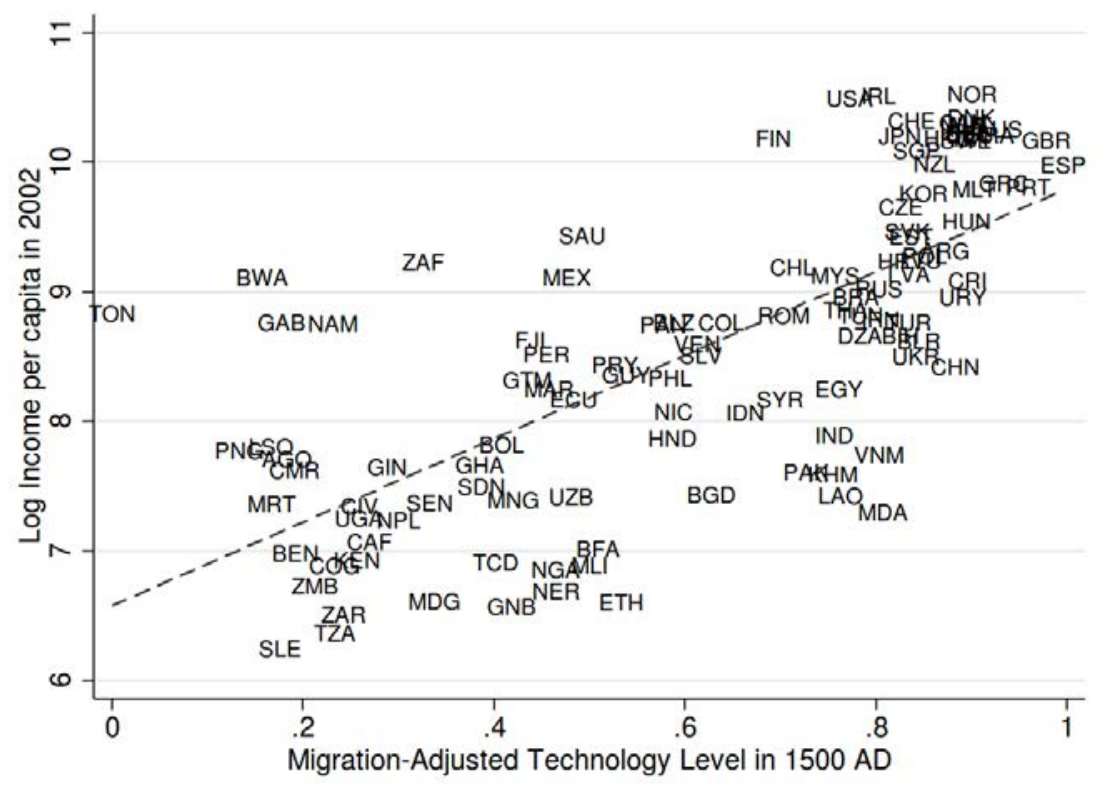

institutions may effectively block the diffusion of new technologies. ${ }^{27}$ Broadly speaking, we can classify these arguments in two groups. One common argument is that bad institutions may not effectively protect the rights of adopters over their technologies or the income they generate. The threat of this risk of expropriation suffices to deter agents from investing in new technologies. A second argument stresses the redistributive consequences of the diffusion of new technologies. For example, Olson (1982) argues that new technologies may eliminate the rents of producers that have significant physical or human capital invested in older technologies. Acemoglu and Robinson (2000) emphasize that the diffusion of some new technologies that facilitate transportation and communication may reduce the political power of some elites. Bad institutions may enable threatened political or economic incumbents to raise barriers to the diffusion of the technologies that jeopardize their economic or political rents.

Despite the abundance of theories that model these logic and narratives that anecdotally provide some evidence, we have few systematic analysis that evaluate the general relevance of political constraints on technology diffusion. Comin and Hobijn (2004) explore the first hypothesis using their sample of 25 technologies and 23 advanced countries. They consider various characteristics of the political institutions of each country as regressors in (28). These include a set of dummies for the type of effective executive (monarch, president, premier or lack of effective executive), a dummy for whether the regime is military, an index of the legitimacy of the party system that measures whether no party is excluded from participating

\footnotetext{
${ }^{27}$ See, for example, the review by Acemoglu et al. (2005) and the references therein.
} 
in the political process. Table 7 reproduces their findings. There are two main observations. First, both not having an effective executive and having a military regime are associated with a lower level of technology in the country. This is consistent with the notion that property right protection is a necessary condition for adopting technologies. Second, an effective legislature is associated with a less intense adoption of technologies. This finding may be surprising, but we try to rationalize it below.

The role of redistributive politics on technology diffusion has also been explored recently. Comin and Hobijn (2009b) bring to the data Olson (1982) theory and explore the significance of barriers erected by incumbent producers on the speed of diffusion of new technologies. Their identification strategy consists in two parts. First, certain institutional attributes affect the political cost faced by the legislature when raising barriers to the diffusion of a new technology. In particular, the cost lobbies must incur to induce legislators to raise diffusion barriers are higher when legislators are not independent, the judicial system is effective, and the regime is democratic and non-military. ${ }^{28}$

Second, the benefits old technology producers enjoy from raising barriers against the diffusion of a new technology depend on certain attributes of the new and old technologies. There are some new technologies that are so superior to the old technology that, even with political barriers, consumers prefer the new technology to the old one. In these cases, old technology producers find no benefit in lobbying for barriers. Thus, the new technology will diffuse quickly regardless of the costs of lobbying. Other new technologies do, however, have close predecessor technologies because the productivity differential between old and new technologies is relatively small. In these cases, old technology producers may benefit from barriers to the new technology because in the presence of barriers consumers may prefer to use the old technology. The speed of diffusion of these new technologies depends, therefore, on the cost of erecting barriers. When it is costly to raise political barriers, lobbying is unsuccessful, barriers are not raised, and new technologies diffuse quickly. Conversely, when the cost of raising barriers is low, the legislative authority accepts the old technology's lobbying bribes and raises barriers that slow down the diffusion of the new technology.

It follows from these two premises that, the effect of lobbies on technology diffusion can be identified by the differential effect of institutions. If lobbies matter, institutions that affect the political cost of erecting barriers should have a differential effect on the diffusion of technologies with close predecessors relative to those without close predecessors.

Comin and Hobijn use a sample of 20 technologies, 23 countries over the last 200 years from HCCTAD. Their main finding is that variables that affect the cost of lobbying such as how democratic is a country, the judicial effectiveness and whether the regime is military have a differential effect on the diffusion of technologies with a close predecessor of the expected

\footnotetext{
${ }^{28}$ See, Myerson (1993), Ferejohn (1986), Persson et al. (2000), Kunicová and Rose-Ackerman (2005), Persson et al. (2003) and Besley and Case (1995).
} 
sign (higher cost is associated with higher differential adoption). Similarly, Comin and Hobijn (2009b) find that a more independent legislative power is associated with a negative differential diffusion of the technologies with a close predecessor. They rationalize as evidence that, other things equal, a more independent legislature faces less constraints to pass regulations that favor powerful lobbies, which tend to be those of the incumbent technologies. It is important to stress that these results are robust to including country and year dummies as well as country-dummies that are specific to incumbent and new technology groupings.

Though the evidence presented in Comin and Hobijn (2009b) is supportive of the role of distributive politics on technology diffusion, it is important to be aware of two important limitations of this study. First, it evaluates only one particular theory of redistributive politics and technology diffusion Olson, 1982. Second, the sample used covers only advanced economies. Hence, more studies are necessary to made an accurate assessment of the global significance of political institutions on technology adoption patterns.

Trade Openness One of the reasons why institutions may matter is because they affect the policies implemented by governments. Among those, trade policies have probably received most attention. Sachs and Warner (1995), Frankel and Romer (1999) and Feyrer (2009a,b) showed that trade has a significant impact on income growth. A natural question is whether the channel by which trade affects growth is technology adoption. This question is still largely unexplored. All the existing evidence we are aware off basically consists in including measures of trade openness in specification (28). ${ }^{29}$ Comin and Hobijn (2004) find that countries whose trade makes up a larger part of its GDP are the front runners in technology adoption. The coefficient on openness is significant for the bulk of our specifications and its magnitude implies that countries that are $12-15 \%$ more open than others will be $1 \%$ ahead in the adoption of technologies.

Related to this, Coe and Helpman (1995) find a strong effect of the technological advancement of the trading partner on TFP. Again, it is natural to inquire whether this effect operates through the adoption of new technologies. To explore this hypothesis, Comin and Hobijn (2004) include as regressors the trade-weighted averages of GDP and the trade-weighted level of technology adoption for the trading partners. Somewhat surprisingly, they obtain a negative coefficient which they interpret as evidence that the effect of trade on TFP may be affecting factors other than a more intensive adoption of technology. Again, this seems an area where there is room for more research in the future.

\footnotetext{
${ }^{29}$ Lucas et al. (2011) and Perla et al. (2012) provide structural models of trade and growth that account for the diffusion process. They rely on calibrations to assess the link between trade and growth.
} 


\subsection{Demand}

The level of demand is an important determinant of the return to adopting a technology. A higher demand allows adopters to cover the sunk costs of adoption among more buyers of the goods and services produced with the technology. Therefore, increasing the profitability of the investment. Even when the costs of adoption are negligible, we should expect larger demand for the goods and services that embody a technology in places and times where aggregate demand is higher. This is clear from equation (22).

The notion that demand is an important driver of technology has been recognized at least since Schmookler (1966). Schmookler argued that demand should play a key role both in the amount of innovation activity as well as in the sectors where it was concentrated. He brought this hypothesis to the data by exploring how patenting activity in capital intensive sectors correlated with lagged investment (his measure of demand pull). Both in cross-sections of sectors and in the time series within sectors, Schmookler (1966) found a strong co-movement between lagged investment and patenting activity. ${ }^{30}$ Subsequent research has explored the cyclicality of R\&D activities (Griliches, 1990, Fatas, 2000, Comin and Gertler, 2006). The robust finding is that $R \& D$ expenditures positively co-move with output at business cycle frequencies and that the co-movement increases when we consider lower frequencies. ${ }^{31}$ Most of this evidence is at the aggregate level. The exception is Barlevy (2007), who found a positive co-movement between firm-level growth in real R\&D expenditures and 4-digit sector level growth in aggregate demand.

Nevertheless, R\&D and technology adoption are distinct activities that are undertaken by different companies and that also differ in their geography. Is there evidence of the importance of demand pull forces for the adoption of new technologies?

In Table 7, Comin and Hobijn (2004) introduce the log of income per capita as a control (see equation 28). They find that the elasticity of technology with respect to income is around 1 (and significant at the $1 \%$ level). Of course, the concern that per capita income captures variables other than demand is legitimate. This concern, however should be mitigated to some extent by the fact that the estimate of the income elasticity does not decline after controlling for potential omitted variables such as institutions, openness, human capital and adoption of predecessor and complementary technologies.

Comin (2009) follows a different approach to estimating the elasticity of technology with respect to income. Following the traditional diffusion literature, he poses a S-shaped diffusion process modified to allow for the speed of diffusion to depend on deviations from trend of GDP. In particular, consider the $(\log )$ ratio of adopters $\left(m_{j t}\right)$ to non-adopters $\left(M-m_{j t}\right)$ for

\footnotetext{
${ }^{30}$ See Scherer (1981) for a confirmation of these findings in a larger number of sectors and other indicators of demand pull.

${ }^{31}$ Specifically, cycles with periods between 8 and 50 years.
} 
a generic technology $j$

$$
r_{j_{t}} \equiv \ln \left(m_{j t} /\left(M-m_{j t}\right)\right)
$$

Note that the first difference of $r_{j t}$ is the speed of diffusion of the technology. If the share of adopters $\left(m_{j t} / M\right)$ follows a logistic curve, then the speed of diffusion $\left(\triangle r_{j_{t}}\right)$ is constant. Comin explores the constancy of the speed of diffusion in a sample of 22 manufacturing processes in the UK. ${ }^{32}$ He finds that the speed of diffusion is far from constant and it tends to decline as the technology diffuses. To capture this pattern and to explore the cyclicality of the speed of technology diffusion, Comin (2009) poses the following specification

$$
\triangle r_{j_{t+1}}=\beta_{j}+\alpha_{1} t_{j}+\alpha_{2} t_{j}^{2}+\gamma y_{2200 t}+\epsilon_{j t}
$$

where $t_{j}$ is the number of years since the invention of technology $j$, and $y_{2200 t}$ is GDP detrended so that we keep fluctuations with periods between 2 and 200 quarters.

Comin (2009) obtains an estimate of the elasticity of the speed of diffusion with respect to detrended GDP of 5.12 with a $95 \%$ confidence interval of $(1.9,8.34)$. Figure 5 plots the implications of equation (29) for the diffusion of numerical control turning machines. The black solid line represents the actual evolution of the share of adopters; the line with triangles plots the diffusion path predicted by equation (29); the line with starts plots the evolution of cumulative detrended output; and the line with squares plots the diffusion path predicted by equation (29) when the effect of the cycle on diffusion is ignored.

Ignoring the business cycle component in equation (29) has important consequences. Eight years after the introduction of numerical control turning machines in the UK only seven percent of potential adopters had adopted the technology. The model without the cycle component predicts that over 30 percent of potential adopters should be using the technology. One explanation for the slow diffusion of numerical control turning machines in the UK is that at that point it had been for eight consecutive years below trend. As a result producers faced a low demand and had few incentives to invest in the new technology. Once this effect is taken into account, equation (29) predicts that after eight years the diffusion of numerical control turning machines in the UK should have been 13 percent, much closer to the actual seven percent.

This evidence raises the question of why are the estimates for the income elasticity of technology so different in Comin (2009) and Comin and Hobijn (2004). Is the difference due to differences in the measurement of technology, or to differences in the income frequencies

\footnotetext{
${ }^{32}$ The data comes from Davies (1979) and spans from WWII to the late 1970s. The technologies include special presses, foils, wet suction boxes, gibberellic acid, automatic size boxes, accelerated drying hoods, electrical hygrometers, basic oxygen process, vacuum degassing, vacuum melting, continuous casting, tunnel kilns, process control by computer, tufted carpets, computer typesetting, photo-electrically controlled cutting, shuttleless looms, numerical control printing presses, numerical control turning machines and numerical control turbines.
} 
Figure 5: Diffusion of Numerical Control Turning Machines in the UK

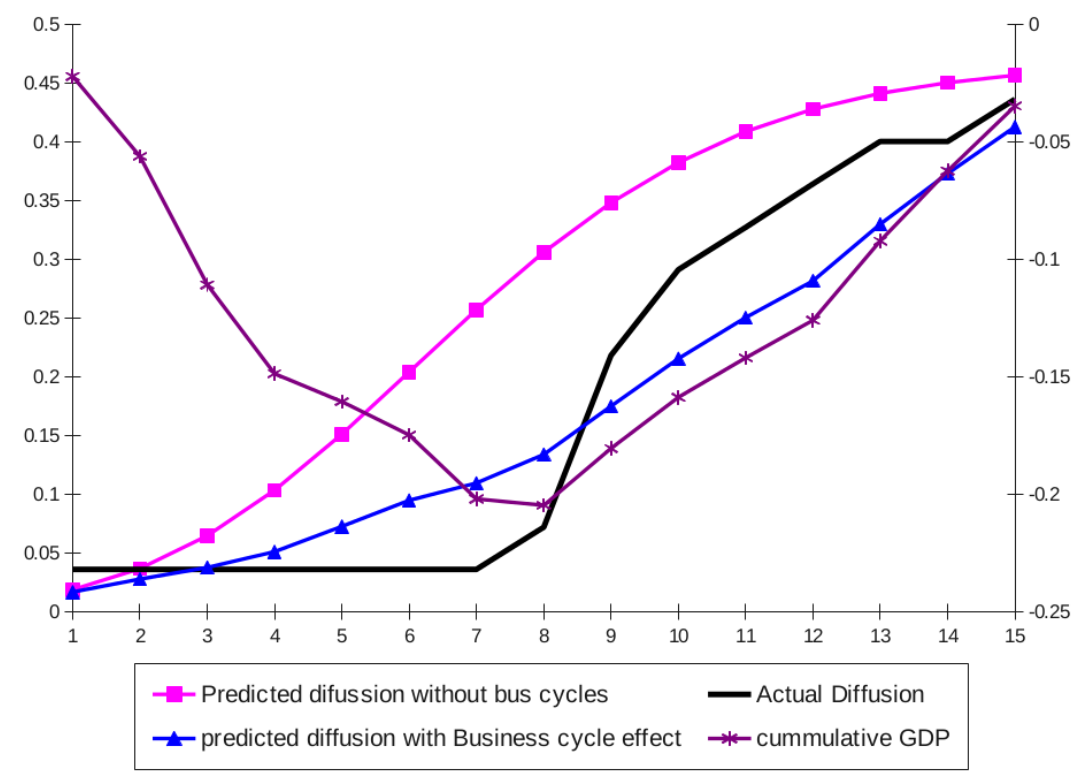

considered?

Findings in Comin and Mestieri (2010) may start to shed some light on this question. Specifically, they estimate a version of equation (25) where they decompose GDP between the cyclical and the trend component, and allow for different elasticities of technology with respect to each component. The cyclical component is captured by HP-filtered output and the non-cyclical component is the HP-trend. Comin and Mestieri use the same 15 technologies considered in Comin and Hobijn (2010), and estimate these elasticities for the U.S. Furthermore, they restrict the elasticities of technology with respect to each component of income to be the same across technologies. They obtain an income elasticity of 2.2 with respect to the HP-trend and of 6.6 with respect to the cyclical component of GDP. These estimates are consistent with the evidence presented above. In particular, they seem consistent with a much higher elasticity of technology diffusion with respect to cyclical measures of output than with respect to the trend in output with the former in the vicinity of 5 and the latter between 1 and 2. These estimates also confirm the importance of aggregate demand for technology diffusion.

\section{Effects of Technology Adoption}

In the final section of this chapter, we explore the macroeconomic consequences of technology. We organize our exposition according to the frequency of interest. First, we explore the roles played by technology in business cycle fluctuations. Then, we perform a development 
accounting exercise. We quantify the contribution of cross-country differences in technology diffusion to cross-country differences in income. Finally, we explore how changes in technology adoption patterns over time help us explain cross-country growth differences over protracted periods of time.

\subsection{Business Cycles Fluctuations}

The role conferred to technology in business cycle analysis has traditionally been reduced to an exogenous disturbance. This is a natural consequence of using the neoclassical growth model as the workhorse framework for business cycle analysis. Real business cycle models (e.g., Kydland and Prescott, 1982) intend to synthesize growth and business cycle fluctuations by introducing stochastic disturbances to the exogenous technology process. The propagation of the shocks is then governed by the dynamics of capital accumulation in the neoclassical model. In early versions of RBC models, total factor productivity (TFP) is interpreted as a measure of the technology in the economy. Growth in TFP drives growth in the long term. TFP has two components. A deterministic trend and exogenous, stochastic deviations from the trend that drive short-term fluctuations in the economy. Subsequent approaches to business cycle analysis have minimized the role of technology shocks as a source of business cycle fluctuations (Galí, 1999) and have re-interpreted the observed short-term fluctuations in TFP as reflecting cyclical variation in the intensity of use of the factors of production or in the degree of competition (Burnside et al., 1995 and Basu and Fernald, 1997).

Next, we review two new lines of work on the role of technology on business cycle fluctuations. The first re-examines the classical question of the importance of technology shocks for business fluctuations by using more direct measures of technology in the identification of technology shocks. The second line of work proposes technology as a propagation mechanism based on the evidence discussed above on the cyclicality of $R \& D$ expenditures and the speed of diffusion of technology.

\subsubsection{Shocks}

The identification of technology shocks has been challenging in macroeconomics. Traditional approaches involve using indirect inference techniques based either or modified Solow residuals (e.g., Basu, 1996) or on restrictions on the responses from vector-autoregression (VAR) models

(e.g., Galí, 1999). Alexopoulos (2011) revises the classical question of what is the short term effect of a technology shock using her technology books measure to identify technology shocks. To explore this issue, she detrends the measures of the number of technology books edited using a band-pass filter that permits her to consider two types of frequencies: the business cycle (periods between 2 and 8 years) the medium term cycle (periods between 2 and 30 
years).$^{33}$

Alexopoulos shows that both at high and medium term frequencies, her technology measures lead GDP fluctuations. The highest correlations are between the number of books published on computer software and hardware and GDP at $t+1$ which she finds to be 0.47 . Technology books also lead investment and TFP by one or two years, specially when considering medium term cycles. ${ }^{34}$ Interestingly, the number of technology books edited have a sizable volatility both over the business cycle and the medium term cycle. As a way of comparison. the standard deviation of the high frequency measure of technology books edited with lowest volatility-Alexopoulos has 5 different measures- has a standard deviation of $3.5 \%$ vs. $1.4 \%$ for GDP. Estimating a bivariate system where log GDP is ordered first and the technology measure second, she finds that, at a 3 years horizon, technology accounts for at least $9 \%$ of business fluctuations in $\log$ GDP and, at a 9 years horizon, this figure raises to $37 \%$. These figures suggests that fluctuations in the technology available to firms (as proxied by the number of technology books edited) may be a significant source of business cycles fluctuations.

\subsubsection{Propagation mechanisms}

As showed by Cogley and Nason (1995), capital accumulation dynamics are a weak propagation mechanism. The persistence of RBC models is basically the persistence of their shocks. As a result, these models do not explain the persistence of macro variables, they just assume

it (in the form of persistent shocks). This approach is clearly unsatisfactory. On the one hand, macro shocks typically are not as persistent as macro series. On the other, it is of critical importance both for descriptive and prescriptive reasons to understand what mechanisms propagate short term shocks and generate effects that last for several quarters and years.

Comin and Gertler (2006) explore this question by deviating from the standard macro framework. In particular, based on the evidence that R\&D and adoption investments are procyclical, they challenge the view that technology is exogenous. They do that by building a business cycle model where, as in endogenous growth models (e.g., Romer, 1990), technology is the result from purposeful investments by agents/firms in developing and adopting new technologies. The investments in upgrading technology (by innovation or adoption) affect the stock of technologies available for production. In this way, technology emerges naturally as a new state variable that may significantly affect the dynamic response of the model to business cycle shocks.

\footnotetext{
${ }^{33}$ Note that she uses an upper bound that is slightly lower than the one used in Comin and Gertler (2006).

${ }^{34}$ With respect to hours, Alexopoulos finds that there is no significant contemporaneous effect of technology on hours work at the high frequency but she finds strong positive effects of current technology on hours at $t+1$ and at $t+2$. Over the medium term, she finds a negative and sizable contemporaneous association between hours and technology and a milder effect after one and two years.
} 
Next, we sketch a simplified version of the framework developed in Comin and Hobijn (2007) and review its implications.

A business cycle framework with endogenous technology Our description focuses mostly in the production side of the economy. This version of the framework is a one sector model with development and adoption of intermediate goods which affect the efficiency of production in the economy.

Final output.- Final output is produced competitively according to

$$
Y_{t}=\left(\left(U_{t} K_{t}\right)^{\alpha} L_{t}^{1-\alpha}\right)^{\gamma} M_{t}^{1-\gamma}
$$

where $U_{t}$ denotes the intensity of utilization of capital, $K_{t}, L_{t}$ denotes hours worked and $M_{t}$ denotes the materials used in production. Utilization comes at the cost of a faster depreciation of capital. Materials are produced competitively combining differentiated intermediate goods according to

$$
M_{t}=\left(\int_{0}^{A_{t}} x_{i t}^{1 / \theta}\right)^{\theta},
$$

where $\theta>1$ will also be the markup charged by the producer of intermediate good $i$. It takes one unit of final output to produce one unit of any intermediate good. $A_{t}$ denotes the number of intermediate goods available for production at time $t$. Note that if producers use the same number of units of all intermediate goods available for production (e.g., $x_{t}$ ), then (30) can be expressed as

$$
Y_{t}=A_{t}^{(1-\gamma)(\theta-1)}\left(\left(U_{t} K_{t}\right)^{\alpha} L_{t}^{1-\alpha}\right)^{\gamma}\left(A_{t} x_{t}\right)^{1-\gamma} .
$$

The last term in (31) is the amount of output used to produce intermediate goods and the first term is the technological component of TFP.

Adoption.- Intermediate goods are first invented and then are adopted for production. We first characterize the adoption process conditional on the available set of technologies, and then describe the research and development process that leads to new technologies.

Let $Z_{t}$ denote the stock of invented technologies. The stock of not-yet-adopted technologies is $Z_{t}-A_{t}$. Each period, a fraction of the available new technologies become usable. Whether a technology becomes usable is a random draw with success probably $\lambda_{t}$. Once a technology is usable, all firms are able to employ it immediately. Note that under this setup there is slow diffusion of new technologies on average (as on average there is a lag between their invention and adoption dates). Furthermore, aggregation is simple as once a technology is in use, all firms have it.

Formally, the number of adopted technologies, $A_{t}$ is given by

$$
A_{t}=\lambda_{t}\left[Z_{t-1}-A_{t-1}\right]+\phi A_{t-1}
$$


with $0<\phi<1$ representing the probability that the technology has not become obsolete in one period, and $0<\lambda_{t}<1$. We assume that $\lambda_{t}$ is given by the following function

$$
\lambda_{t}=\lambda\left(\Gamma_{t} h_{t}\right)
$$

with $\lambda^{\prime}>0, \lambda^{\prime \prime}<0$, where $\Gamma_{t}$ is the scaling factor that guarantees the existence of a balancedgrowth path and exogenous to the adopter and $h_{t}$ are the resources devoted to adopting a technology in time $t .^{35}$

If $\phi$ is close to 1 , it follows from (32) that transitory changes in $\lambda_{t}$ will have transitory changes in the growth rate of $A_{t}$, but close to permanent changes in the level of $A_{t}$. This property is key to making endogenous technology a powerful propagation mechanism. However, it is not sufficient. In addition, it is necessary that $\lambda_{t}$ is pro-cyclical. To explore the cyclicality of $\lambda_{t}$, we next endogenize it.

The value to the adopter of successfully bringing a new technology into use, $v_{t}$, is given by the present value of profits from operating the technology. Profits each period $\pi_{t}$ arise from the fact that the producer of the new good is a monopolistic competitor. Accordingly, given that $R_{t+1}$ is the one period discount rate between $t+1$ and $t$, we can express, $v_{t}$, as

$$
v_{t}=\pi_{t}+\phi E_{t}\left[\frac{v_{t+1}}{R_{t+1}}\right] .
$$

If an adopter is unsuccessful in the current period, he may try again in the subsequent period to make the technology usable. Let $w_{t}$ be the value of acquiring an innovation that has not yet been adopted. $w_{t}$ is given by

$$
w_{t}=\max _{h_{t}}-h_{t}+\phi E_{t}\left[\frac{\left[\lambda\left(\Gamma_{t} h_{t}\right) v_{t+1}+\left(1-\lambda\left(\Gamma_{t} h_{t}\right)\right) w_{t+1}\right]}{R_{t+1}}\right] .
$$

At the margin, adopters determine how much to spend in adopting a technology by equalizing the marginal cost and the expected marginal benefit from adoption:

$$
1=E_{t}\left[R_{t+1}^{-1} \phi \Gamma_{t} \lambda^{\prime}\left(\Gamma_{t} h_{t}\right)\left(v_{t+1}-w_{t+1}\right)\right]
$$

The expected marginal benefit has three terms. The first captures the discounting of the potential benefits from adoption (i.e., $\left.R_{t+1}^{-1} \phi\right)$; the second captures the marginal increase in the probability of succeeding in adopting when firms invest one extra unit of output (i.e., $\left.\Gamma_{t} \lambda^{\prime}\left(\Gamma_{t} h_{t}\right)\right)$; the third captures the capital gain that occurs when an intermediate good becomes adopted (i.e., $\left.v_{t+1}-w_{t+1}\right)$. When the economy is booming, the expected capital gain increases because of the higher demand of adopted intermediate goods. Firms respond to

\footnotetext{
${ }^{35}$ Comin and Gertler (2006) model $\Gamma_{t}$ as inversely proportional to the (wholesale) value of capital. It is important that $\Gamma_{t}$ is smooth.
} 
this by investing more resources in adoption $\left(h_{t}\right)$. This is why adoption expenditures and the speed of diffusion of technologies, $\lambda_{t}$, are pro-cyclical in the model.

Innovation.- Now that we have solved for the adoption process given the number of available technologies, we need to derive the equations that determine the number of available innovations, $Z_{t}$.

New technologies are developed through R\&D. Each innovator, indexed by $p$, faces the following technology to develop new intermediate goods

$$
Z_{t+1}(p)-Z_{t}(p)=\varphi_{t} S_{t}(p)-\phi Z_{t}(p)
$$

where $Z_{t}(p)$ denotes the stock of (non-obsolete) intermediate goods she has developed up to time $t, S_{t}(p)$ is the number of units of output she devotes to $\mathrm{R} \& \mathrm{D}$ and $\varphi_{t}$ is the productivity of the R\&D as perceived by the individual innovator. As in Romer (1990), the linear formulation permits a simple decentralization of the innovation process. ${ }^{36}$

We assume that $\varphi_{t}$ depends on the aggregate values of the stock of innovations, $Z_{t}$, the scaling factor, $\Gamma_{t}$, and research and development $S_{t}$, and the stock of innovations as follows:

$$
\varphi_{t}=\chi Z_{t}\left(S_{t}\right)^{\rho-1}\left(\Gamma_{t}\right)^{\rho}
$$

with $0<\rho \leq 1$ and where $\chi$ is a fixed scale parameter. This formulation allows for aggregate congestion in R\&D investments. ${ }^{37}$

The linearity of the R\&D technology as perceived by the individual researchers together with a free entry assumption implies that each new product developer $p$ must break even. As a result, the resources invested in $\mathrm{R} \& \mathrm{D}$ by the $p^{\text {th }}$ innovator satisfy the following arbitrage condition:

$$
E_{t}\left[\frac{w_{t+1}}{R_{t+1}}\right]-1 / \varphi_{t}=0
$$

where the first side is the discounted marginal benefit from an innovation and the left side is the marginal cost in units of final output. Note that the pro-cyclicality of $w_{t+1}$ will tend to generate pro-cyclical R\&D expenditures in equilibrium.

The resulting law of motion for the number of intermediate goods, $Z_{t}$, is

$$
Z_{t+1}-Z_{t}=Z_{t} \chi\left(S_{t} / P_{t}^{I} K_{t}\right)^{\rho}-(1-\phi) Z_{t}
$$

The model is closed by adding a law of motion for capital and the preferences of consumers

\footnotetext{
${ }^{36}$ We differ from Romer (1990), however, by having the innovation technology use as input a final good composite of capital and labor, as opposed to just labor. See also Barlevy (2007) for a discussion of the relevance of this choice.

${ }^{37}$ As with Romer, there is a positive spillover of the current stock of innovations on the creation of new products, i.e. $\varphi_{t}$ increases linearly in $Z_{t}$.
} 
which are standard.

Impulse Response functions Comin and Gertler (2006) study a two-sector version of the model we just sketched and introduce shocks to the wage markup. These are non-technological shocks that capture frictions in labor markets and that are isomorphic to shocks to labor income tax and similar to money shocks. Figure 6 reproduces the impulse response of their model (solid) and compare it to a version of the model where the endogenous technology mechanisms have been shut down.

The increase in the wage markup effectively raises the price of labor, reducing labor demand and output. Both the initial impact and the impact over time on output is larger in the model with endogenous technology. Over time, output climbs back to trend, but does not make it back all the way due to the endogenous permanent decline in productivity. This is captured by the evolution of TFP. The initial decline in measured TFP results mainly from variable factor utilization. Over time, there is a decline in true productivity relative to trend. In particular, the initial contraction in economic activity induces a drop in both $R \& D$ and the rate of technology adoption. The temporary drops in R\&D and adoption slow down the rate at which new technologies are incorporated into production, ultimately leading to a permanent drop relative to trend in total factor productivity and labor productivity. In contrast, the model without endogenous productivity, output simply reverts back to its initial steady state. Hence, the propagation power of endogenous technology mechanisms.

Applications The framework outlined above has shed light into business cycle phenomena and historical episodes that are hard to rationalize by standard macro models.

One extreme case of a persistent economic downturn is Japan's so-called Lost Decade of the 1990s, when that country experienced very low growth for a whole decade despite the fact that the shocks that hit the economy lasted, at most, for three years. This is puzzling for standard macro models because they predict a quick recovery of the economy once the shocks are over. More elaborated theories based on realistic features of Japan's context such as zombie companies (e.g., Caballero et al., 2008) or policy mistakes could increase the recession's duration. The endogenous technology framework can provide a natural complement for these theories. Consistent with the model's predictions, Japanese firms did, in fact, slow down their R\&D intensity and slowed the adoption rate of new technologies during the 1990s, falling behind Korea in computer and internet-usage rates. Comin (2011) documents these facts and explores their consequence for the dynamics of output showing that they contribute significantly to the protractedness of the lost decade during the 1990s.

Standard macro models have had trouble reconciling the empirical pro-cyclicality of stock prices and the counter-cyclicality of the relative price of investment. The traditional strategy has been to use unrealistic adjustment costs to new investment. Two sector versions of the 
Figure 6: Impulse Response Functions
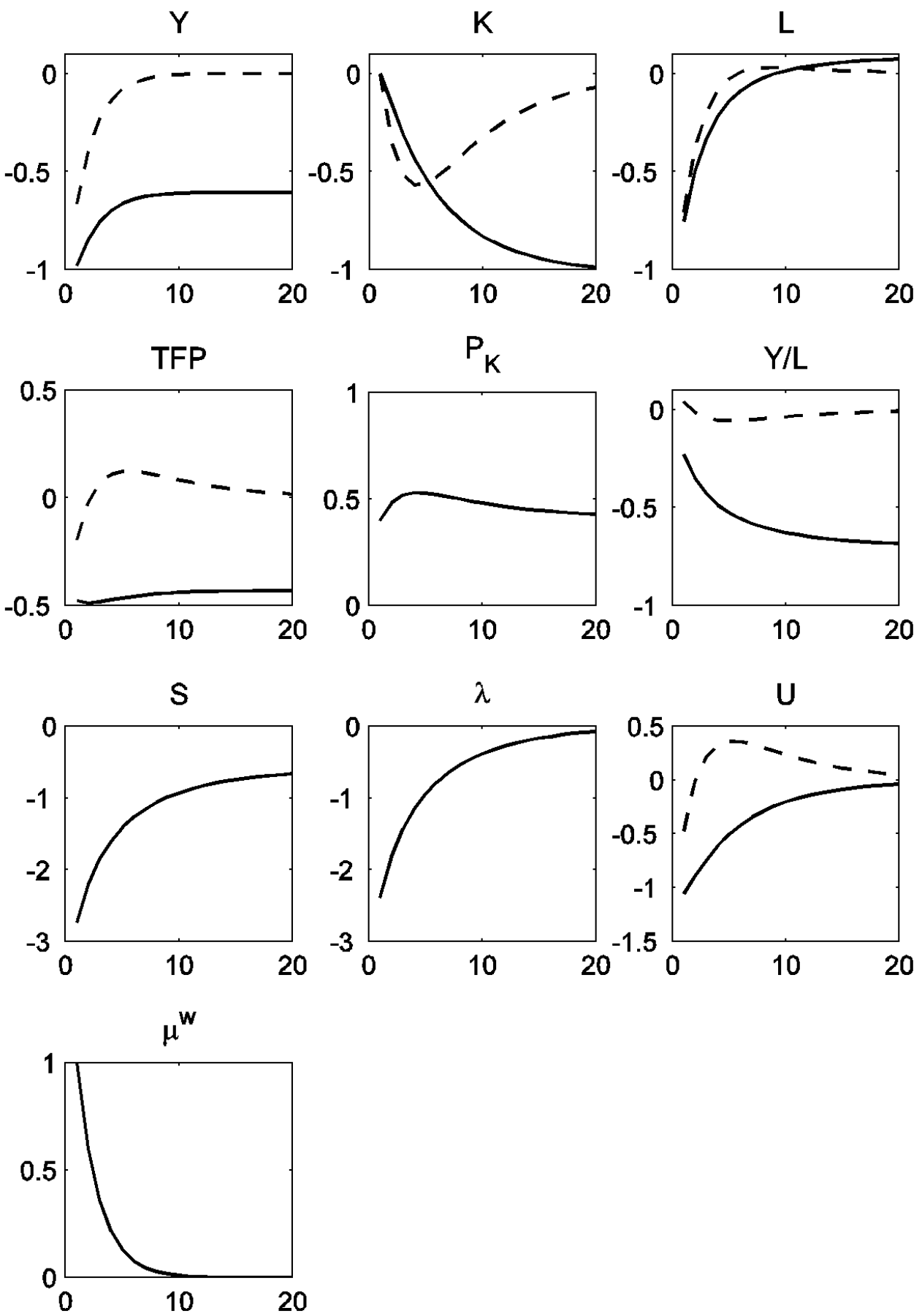
framework can rationalize the cyclical properties of stock prices and the relative price of capital. Intuitively, endogenous improvements in the productivity of the capital producing sector will lead to a counter-cyclical cost of production of investment goods and hence of the relative price of investment. Once technology is endogenous, their price is much more than the market value of installed capital. Their price includes the market value of the current and future technologies they will develop. These technological components of a company's value are pro-cyclical and fluctuate much more than the price of capital, hence dominate the value of capital in determining the cyclicality of stock prices. ${ }^{38}$

Endogenous technology models of business fluctuations may also help us understand better international co-movement patterns. Shocks to developed economies have large and persistent effects in developing countries (see Comin et al., 2009b and the references therein). Standard international macro models struggle to explain the magnitude of these effects. In these models, domestic impulses only affect other economies by reducing demand for their exports. This channel is insufficient, both in the data and in the models, to account for the magnitude of the international propagation of shocks we seem to observe.

An additional international linkage arises when the technology available for production may be affected by disturbances to other economies. Comin et al. (2009b) document that the number of new technologies that diffuse from the United States or Japan to their main trade partners in the developing world is pro-cyclical both with respect to the business cycle in the developed and in the developing economy. Building a two country extension of the framework outlined above, they show that this mechanism is sufficient to generate an international propagation of fluctuations between developed and developing countries similar to what we observe in the data.

\subsection{Development}

The model presented in section 2.3.3 can be used to explore the aggregate implications of technology diffusion for income and for income dynamics (Comin and Hobijn, 2010, Comin and Mestieri, 2010, 2013). To this end, we take advantage of the aggregate representation of the model. Normalizing aggregate labor to one, aggregate output is given by

$$
Y=A X^{\alpha} L^{1-\alpha}=A X^{\alpha}=A^{1 /(1-\alpha)}(\alpha)^{\alpha /(1-\alpha)},
$$

with

$$
A=\left(\int_{-\infty}^{\bar{\tau}} Z_{\tau}^{\frac{1}{\theta-1}} d \tau\right)^{\theta-1}
$$

where $\bar{\tau}$ denotes the most advanced technology adopted in the economy.

\footnotetext{
${ }^{38}$ See Comin et al. (2009a). Also, see Santos and Iraola (2010) for an exposition of the determinants of stock prices in the Comin and Gertler (2006) model.
} 
These equations imply that output dynamics are completely determined by the dynamics of aggregate productivity, $A$. A sufficient condition to guarantee the existence of a balanced growth path is that $D_{\tau}$ and $a_{\tau}$ are constant across technologies - denoted by $D$ and $a .{ }^{39}$ Making the simplifying (and empirically relevant) assumption that $\theta=\mu$, aggregate productivity can be computed in closed form, ${ }^{40}$

$$
A(t)=\left(\frac{(\theta-1)^{2}}{(\gamma+\chi) \chi}\right)^{\theta-1} a e^{(\chi+\gamma)(t-D)} .
$$

This expression shows that higher intensity of adoption, $a$, and shorter adoption lags, $D$, lead to higher aggregate productivity. Along this balanced growth path, productivity grows at rate $\chi+\gamma$ and output grows at rate $(\chi+\gamma) /(1-\alpha) \cdot{ }^{41}$

These expressions can be used to explore the relevance of technology diffusion for crosscountry differences in productivity. In particular, the model implies that the (log) gap in productivity between country $c$ and the average of the Western countries is equal to

$$
y_{c}-y_{w e s t}=\frac{a_{c}-a_{w e s t}}{1-\alpha}+\frac{\chi+\gamma}{1-\alpha}\left(D_{w e s t}-D_{c}\right) .
$$

where $a_{c}$ and $D_{c}$ are respectively the average intensive margin and adoption lag in country $c$. Using our estimates from section (2.3.4), we compute $a_{c}$ and $D_{c}$ as follows:

$$
a_{c}=\frac{1}{N_{c}} \sum_{\tau=1}^{N_{c}} a_{\tau c}, \quad D_{c}=\frac{1}{N_{c}} \sum_{\tau=1}^{N_{c}} D_{\tau c}
$$

where $N_{c}$ is the number of technologies for which we have precise estimates in country $c$.

Figures $7 \mathrm{a}$ and $7 \mathrm{~b}$ plot the contribution to TFP of the extensive and intensive margins, which correspond to the first and second terms in equation (41), against log per capita income in $2000{ }^{42}$ The thicker dashed line corresponds to the regression line,

$$
\begin{aligned}
\left(\frac{a_{c}-a_{\text {west }}}{1-\alpha}\right) & =\alpha+\beta\left(y_{c}-y_{\text {west }}\right), \\
\frac{(\gamma+\chi)\left(D_{\text {west }}-D_{c}\right)}{1-\alpha} & =\delta+\pi\left(y_{c}-y_{\text {west }}\right),
\end{aligned}
$$

where we calibrate $\alpha=.3$ and $(\gamma+\chi) /(1-\alpha)=2 \%$ to compute the contribution to TFP of the intensive and the extensive margin. The light gray line in both figures is the $45^{\circ}$ degree line. The slope of the regression lines $(\beta, \pi)$ can be interpreted as contribution of each margin

\footnotetext{
${ }^{39}$ Comin and Hobijn (2010) and Comin and Mestieri (2010) show in their microfounded models of adoption that this is a necessary and sufficient condition. Hence, this is a natural benchmark for us.

${ }^{40}$ This is what we observe in our estimation. We cannot reject the null hypothesis that $\theta=\mu$.

${ }^{41}$ For utility to be bounded, this requires the parametric assumption that $(\chi+\gamma) /(1-\alpha)>\rho$.

${ }^{42}$ The income data is from the Penn World Tables 6.2. Results are very similar using Maddison (2004).
} 
Figure 7: TFP components of the Intensive and Extensive Margins
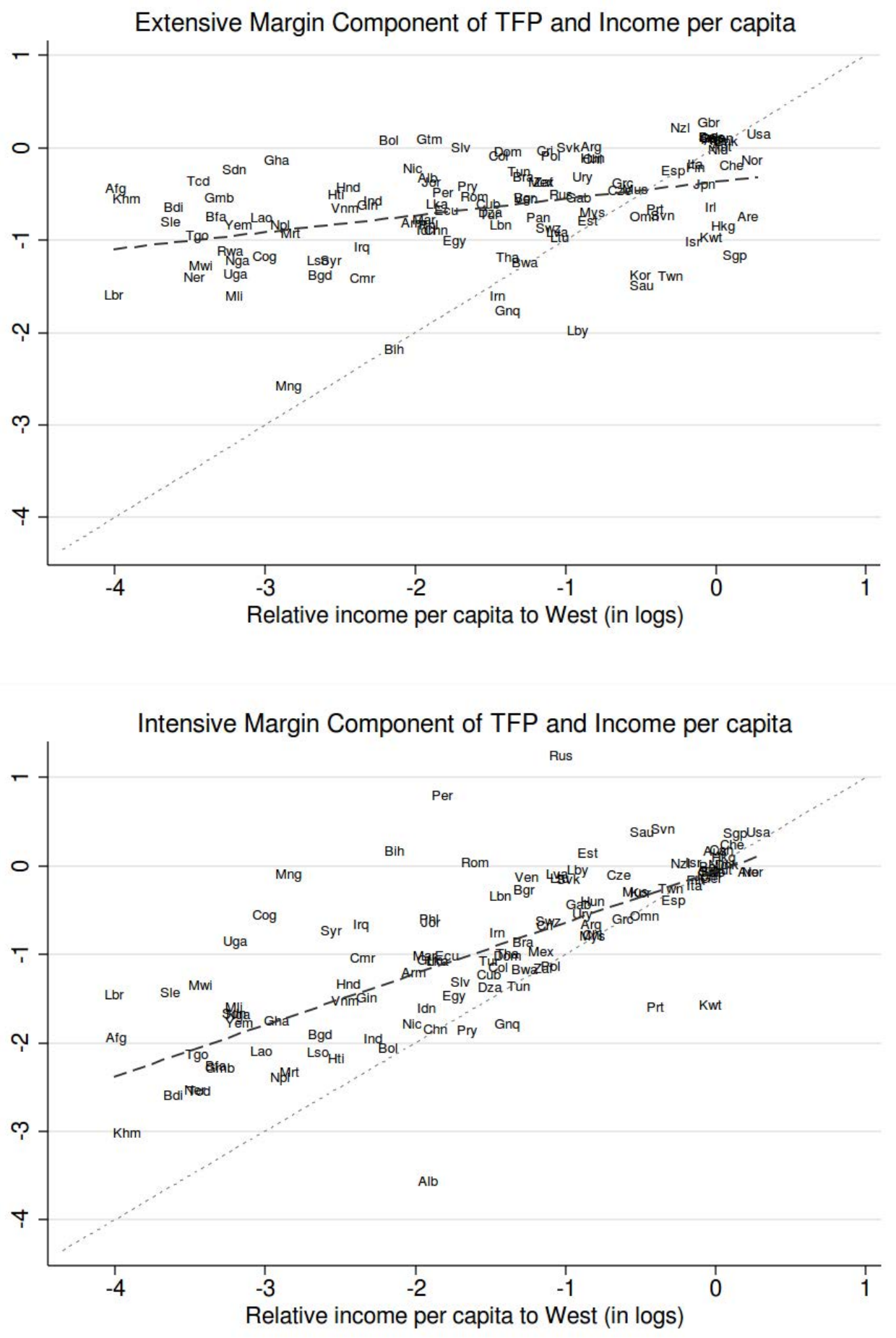
in accounting for differences in income per capita in 2000. If equation (41) were to explain all the income variation today, we would expect the coefficient of (each) regression to be 1 and the data points to lie on the $45^{\circ}$ degree line. We find that the slope for the extensive margin regression displayed in Figure $7 \mathrm{a}$ is $20 \%$, while for the intensive margin is almost $60 \% .{ }^{43}$ If these two margins were uncorrelated we could infer that these two margins alone account for most of the variation (80\%) of income per capita today. If we regress the extensive margin on the intensive margin and use the unpredicted part as the orthogonal component of the intensive margin not predicted by the extensive, we would find that the slope of figure $7 \mathrm{~b}$ goes down to $54 \%$. Thus, most of the variation in income per capita today, over $70 \%$, can be accounted by cross-country differences in the two adoption margins. Among the two, the intensive margin takes the lion's share.

\subsection{Growth}

In this section we study how the evolution of the two margins of adoption affect the evolution of aggregate productivity of the economy. We use the model from Section 2.3.2 to evaluate quantitatively its ability to generate the observed cross-country income growth dynamics over the last 200 years.

Specifically, we focus on three questions: (i) The significance of differences in early adoption to account for cross-country income differences in the pre-industrial balanced growth path; (ii) the protractedness of the model transitional dynamics; and (iii) the model's account of the Great Income Divergence. To this purpose, we keep Maddison (2004)'s division of countries between Western countries and the rest of the world.

Calibration To simulate the model we need to calibrate four parameters. First, we need to specify the path for the world technology frontier. Prior to year $T=1765$ (year in which James Watt developed his steam engine), we assume that the technology frontier grew at $0.2 \%$. This is the growth rate of Western Europe according to Maddison (2004) from 1500 to 1800 . After 1765 , the frontier grows at $(1-\alpha) \cdot 2 \%$ per year. As shown in equation (40), the growth rate along the balanced growth is equal to $(\gamma+\chi) /(1-\alpha)$. Hence, the Modern balanced growth is $2 \%$. The literature has not determined what fraction of frontier growth comes from each of these two sources. Therefore, we split evenly the sources of growth in the frontier between $\gamma$ and $\chi$. We take $\alpha=.3$ to match the labor income share.

\footnotetext{
${ }^{43}$ The $R^{2}$ of these two regressions are .15 and .49 , respectively. If we regress real income per capita in 2000 on the two margins, we find that the combined $R^{2}$ is .58 . These regressions for the intensive margin are done as described in Comin and Mestieri (2010), filtering a common fixed effect across all estimates for a country that are measured in terms of capital. This is motivated by a richer structural model that allows for an additional distortion on the price of capital. This correction reduces the estimated contribution of the intensive margin in this regression. Thus, this is our most conservative estimate. Should we not do this correction, we would find that it accounts for almost $70 \%$.
} 
Finally, we need to calibrate the elasticities of substitution between technologies, which we assume are the same and equal to $1 /(\theta-1)$. We back out the value of $\theta$ from the estimates of $\beta_{\tau 3}$. The average value we estimate for $\theta$ is 1.28 , which is very similar to the values implied by the estimates of price markups from Basu and Fernald (1997) and Norbin (1993). Thus, we set $\theta=1.28$.

Initial income differences It follows from expressions (38) and (40) that, in our model, differences in productivity in the pre-industrial balanced growth path are due to differences in adoption lags and in the intensive margin in the pre-Modern era. Given that we do not have data for pre-Modern technologies, we assume that pre-Modern levels of adoption were constant and coincide with the initial adoption levels that we estimate. Our estimates from Tables 5 and 6 imply that the difference between the average adoption lag in the sample of Western countries and in other countries is 49 years in 1820. The average gap in the (log) intensive margin is 0.39 . With this assumption and using Maddison's estimates of pre-industrial growth in Western Europe (0.2\%) to calibrate the pre-industrial growth rate of the world technology frontier. Equation (40) implies an income gap between Western countries and the rest of the world of $90 \%{ }^{44}$ This is in line with the results from Maddison (2004), who reports an income gap of the same magnitude. Hence, the pre-industrial income differences generated by our model account very well for those observed in the data.

Protracted dynamics Next, we explore the protractedness of the model transitional dynamics. To this end, we consider the average country in our sample. The average country is parametrized so that its adoption lag and its degree of penetration rate $\left(a_{\tau}\right)$ are constant and equal to the average adoption lag and intensive margin across countries over our sample of technologies. In particular, the resulting $D$ is 44 years and the intensive margin is $54 \%$ of the U.S. level.

We model the Industrial Revolution as a one time, permanent increase in the growth of the world technology frontier $(\gamma+\chi)$, so that the balanced growth path increases from $0.2 \%$ to $2 \%$. This view is consistent with Mokyr (1990) and Crafts (1997). Figure 8 plots the transition of the output gap in this representative economy. The output gap is defined as the ratio of output in the Modern balanced growth path relative to current output. In the figure, we can see that the model generates a very slow convergence to the new balanced growth path. The half-life of the output gap relative to the Modern balanced growth path is 117 years while for output growth it is 145 years. These half-lives are an order of magnitude higher than the typical half-life in neoclassical growth models (e.g., Barro and Sala-i-Martin, 2003).

\footnotetext{
${ }^{44}$ That is, $\exp (.2 \% \cdot 49+.39 /(1-\alpha))=1.9$.
} 
There are three reasons why our model generates such protracted dynamics. First, the long adoption lags (44 years) imply that it takes this amount of time for the new technologies (which embody the higher productivity gains) to arrive to the economy. Until then, there is no effect whatsoever in output growth. Second, for a given growth in the Modern sector output, its impact in GDP depends on the share of the Modern sector. Since the Modern sector's share increases slowly, so does aggregate output. Third, the growth rate of the Modern sector is initially very small and grows progressively. ${ }^{45}$

Cross-country evolution of income growth To evaluate the model's power to account for the Great Divergence, we simulate the evolution of output for Western countries and the rest of the world after feeding in a (common) one time permanent increase in frontier growth and the estimated evolutions for adoption lags and the intensive margin for each group of countries reported in Tables 5 and $6 .{ }^{46}$ The results from this exercise are reported in Figure 9 and Table 9.

The model generates sustained differences in the growth rates of Western and non-Western countries for long periods of time. Output growth starts to accelerate at the beginning of the nineteenth century in the Western economy, converging to the steady state growth of $2 \%$ in the early twentieth century. For the non-Western country, instead, growth does not increase from the pre-industrial rate until the end of the nineteenth century. Growth in the nonWestern country slowly accelerates, but it is still around $1.5 \%$ by year 2000 . The gap in growth between both countries is considerable. Annual growth rates differ by more than $0.7 \%$ for over 100 years. The peak gap is reached around 1915 at 1.1\%. From then, the gap declines monotonically until reaching around $0.6 \%$ by 2000. Table 9 reports the average growth and growth gaps of our simulation comparing it to Maddison (2004). The patterns and levels in our data trace quite well Maddison's.

The sustained cross-country gap in growth produced by the model leads to a substantial gap in income per capita. In particular, our model generates a 3.2 income gap between the Western countries and the rest of the world. Maddison (2004) reports an actual income widening by a factor of 3.9 between Western countries and the rest of the world since the Industrial Revolution. Hence, most of the variation (82\%) in the income gap between Western and non-Western countries in the last two centuries is accounted for.

The simulation does also well in replicating the time series income evolution of each country group separately. For Western countries, Maddison (2004) reports a 18.5-fold increase in

\footnotetext{
${ }^{45}$ Comin and Mestieri (2013) analyze the properties of the transitional dynamics of this model providing theoretical ground for this explanation.

${ }^{46}$ We assume that after the last technology invented in our sample (the internet, in 1983), the estimated margins remain constant at their 1983 values. This ensures that both groups of countries exhibit the same long-run growth. This assumption is quantitatively inconsequential, as it only affects the dynamics of the last ten years of our simulations. If anything, it tends to understate the effect of technology dynamics.
} 
Figure 8: Slow transitional dynamics.

(a) Consumption gap (relative to the Modern BGP)

(b) Growth path to Modern BGP
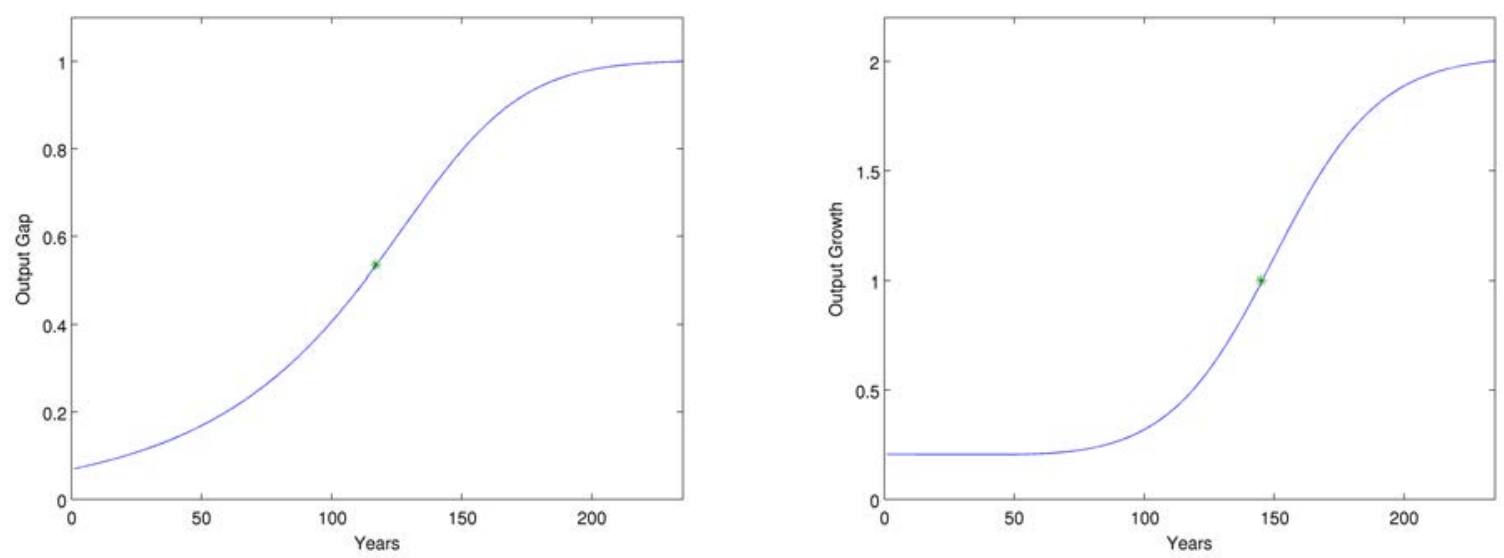

This simulation corresponds to the transition to the new balanced growth path after an acceleration of the technological frontier from .2\% to $2 \%$ for a country with a constant lag as the average lag in our sample (44 years) and average intensive margin (54\% of the Western productivity level). The star * denotes the half-life.

Figure 9: Simulated Growth for Western and Non-Western
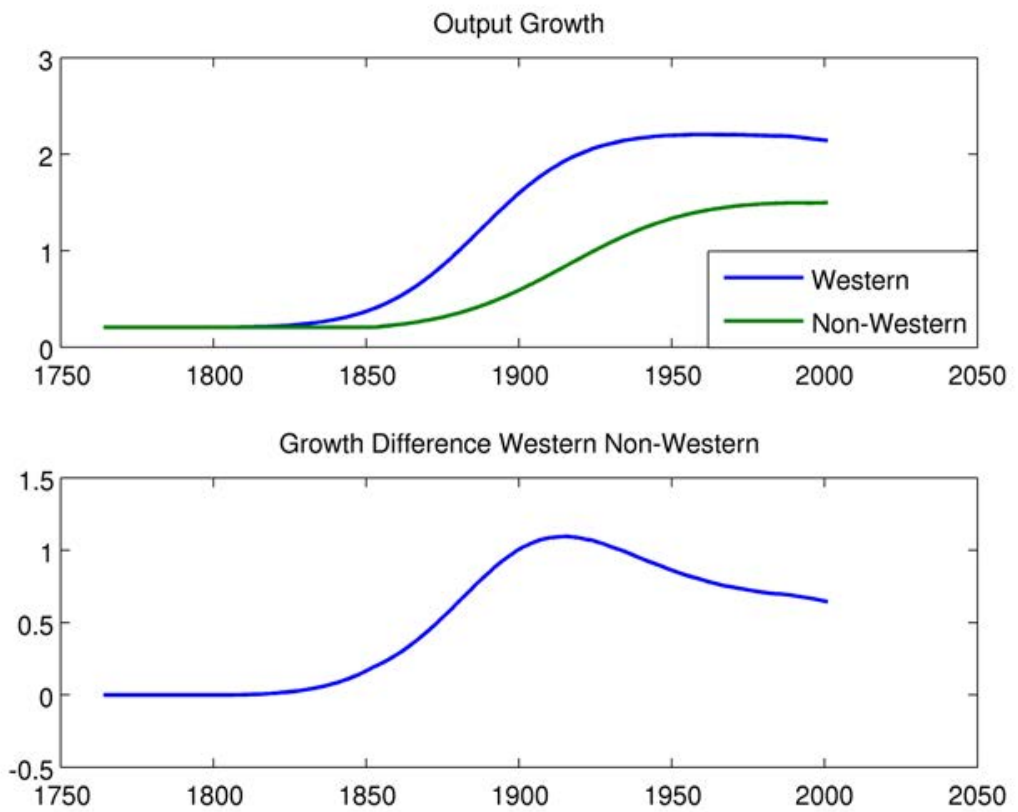

Growth of income per capita in the last 200 years for Western and Non-Western countries imputing the estimated evolution of the intensive and extensive margins to the baseline model. 
Table 9: Growth rates of GDP per capita

\begin{tabular}{llrrr}
\hline \hline & & \multicolumn{3}{c}{ Time Period } \\
\cline { 3 - 5 } Simulation & Western Countries & $1820-2000$ & $1820-1913$ & $1913-2000$ \\
& Rest of the World & $.82 \%$ & $.84 \%$ & $2.15 \%$ \\
& Difference West-Rest & $.65 \%$ & $.49 \%$ & $1.31 \%$ \\
\hline \multirow{2}{*}{ Maddison } & Western Countries & $1.61 \%$ & $1.21 \%$ & $.84 \%$ \\
& Rest of the World & $.86 \%$ & $.63 \%$ & $1.95 \%$ \\
& Difference West-Rest & $.75 \%$ & $.58 \%$ & $.93 \%$ \\
\hline \hline
\end{tabular}

Notes: Simulation results and median growth rates from Maddison (2004). We use 1913 instead of 1900 to divide the sample because there are more country observations in Maddison (2004). The growth rates reported from Maddison for the period 1820-1913 for non-Western countries are computed imputing the median per capita income in 1820 for those countries with income data in 1913 but missing observations in 1820 . These represent 11 observations out of the total 50. We do the same imputation for computing the growth rate for non-Western countries for 1820-2000. This represents 106 observations out of 145 . For the 1913-2000 growth rate of non-Western countries, we impute the median per capita income in 1913 to those countries with income per capita data in 2000 but missing observations in 1913. These represent 67 observations out of the total 145 .

income per capita between 1820 and 2000. Approximately 19\% of this increase occurred prior to 1913. In our simulation, we generate a 14 -fold increase over the same period, and $16 \%$ of this increase is generated prior to 1913. For non-Western countries, Maddison (2004) reports an almost 5-fold increase, with around $37 \%$ of the increase being generated prior to 1913 . Our simulation generates a 4.3 -fold increase in the 1820-2000 period with $32 \%$ of this increase occurring in pre-1913. The fact that we under-predict the time series increase in output reflects, in our view, our omission of factor accumulation dynamics (e.g., human capital), which also contributed to income growth.

The role of the evolution of adoption margins After showing that the model does a remarkable job in reproducing the cross-country dynamics of income growth over the last two centuries, Comin and Mestieri (2013) dissect the mechanisms at work. In particular, we simulate the economy shutting down, sequentially, the dynamics in each adoption margin. From this exercise, we conclude that the large cross-country differences in adoption lags explain much of the income divergence during the nineteenth century. However, the convergence in adoption lags that we have documented would make non-Western countries grow faster than Western countries during the twentieth century. The reason why we do not observe this catchup is the divergence in the intensive margin that we have documented. The magnitude of the divergence in the intensive margin is sufficient to undo the catch-up induced by the converge in adoption lags. In fact, it sustains the gap in growth rates between Western countries and the rest of the world during the twentieth century. Thus, in our simulation, the divergence in penetration rates accounts for the lack of convergence in income per capita between Western 
countries and the rest of the world during the twentieth century.

\section{Concluding remarks}

This chapter has explored three broad questions related to the diffusion of technology: (i) How can we measure technology diffusion and what are the broad patterns we have observed both across countries and over time on technology diffusion?; (ii) what are the main drivers of technology diffusion?; and (iii) what are the macroeconomic consequences of technology diffusion?

Given the strong linkages between these questions, addressing them in a unified way ensures internal consistency and exploits insights that have implications for more than one question. Despite the progress reported, we consider that still there is plenty of room to develop new studies that increase our understanding of these questions. Future work is likely to develop new comprehensive data sets that provide new measures of technology diffusion. Current and future data can be used to explore new implications of technology in new fields such as the development of institutions (e.g., political, educational, financial), the political consequences of technology, and the role of technology in wars and civil conflicts. Probably, where more and most obvious opportunities exist is in exploring the drivers of technology. The work summarized in this chapter as well as other studies have argued that technology is a key driver of cross-country income differences. However, it is still too early to conclusively assess what forces shape technology and how these forces operate over time. There is room both for exploration of new drivers and mechanisms of technology as well as for deeper investigations of mechanisms already discussed in the literature. 


\section{References}

Acemoglu, D., Johnson, S. and Robinson, J. A. (2002). Reversal of fortune: Geography and institutions in the making of the modern world income distribution. The Quarterly Journal of Economics, 117 (4), 1231-1294.

-, - and - (2005). Institutions as a fundamental cause of long-run growth. In P. Aghion and S. Durlauf (eds.), Handbook of Economic Growth, Handbook of Economic Growth, vol. 1, 6, Elsevier, pp. 385-472.

— and Robinson, J. A. (2000). Why did the west extend the franchise? democracy, inequality, and growth in historical perspective. The Quarterly Journal of Economics, 115 (4), $1167-1199$.

Aghion, P. and Howitt, P. (1992). A model of growth through creative destruction. Econometrica, 60 (2), 323-51.

Alexopoulos, M. (2011). Read all about it!! what happens following a technology shock? American Economic Review, 101 (4), 1144-79.

Arellano, M. and Bond, S. (1991). Some tests of specification for panel data: Monte carlo evidence and an application to employment equations. Review of Economic Studies, 58 (2), $277-97$.

Arrow, K. J. (1962). The economic implications of learning by doing. The Review of Economic Studies, 29 (3), 155-173.

Arthur, W. B. (1989). Competing technologies, increasing returns, and lock-in by historical events. Economic Journal, 99, 116-131.

Ashraf, Q. and Galor, O. (2013). The 'out of africa' hypothesis, human genetic diversity, and comparative economic development. American Economic Review, 103 (1), 1-46.

Bandiera, O. and Rasul, I. (2006). Social networks and technology adoption in northern mozambique. Economic Journal, 116 (514), 869-902.

BAnerJeE, A. (1992). A simple model of herd behavior. Quarterly Journal of Economics, 107 (3), 797-817.

BArlevy, G. (2007). On the cyclicality of research and development. American Economic Review, 97 (4), 1131-1164.

Barro, R. J. and Sala-I-Martin, X. (2003). Economic Growth, 2nd Edition. The MIT Press. 
BAsu, S. (1996). Procyclical productivity: Increasing returns or cyclical utilization? The Quarterly Journal of Economics, 111 (3), 719-51.

- and Fernald, J. G. (1997). Returns to scale in u.s. production: Estimates and implications. Journal of Political Economy, 105 (2), 249-283.

Benhabib, J. and Spiegel, M. M. (1994). The role of human capital in economic development evidence from aggregate cross-country data. Journal of Monetary Economics, 34 (2), 143-173.

— and - (2005). Human capital and technology diffusion. In P. Aghion and S. Durlauf (eds.), Handbook of Economic Growth, Handbook of Economic Growth, vol. 1, 13, Elsevier, pp. 935-966.

Besley, T. and CAse, A. (1995). Does electoral accountability affect economic policy choices? evidence from gubernatorial term limits. The Quarterly Journal of Economics, 110 (3), 769-98.

Bockstette, V., Chanda, A. and Putterman, L. (2002). States and markets: The advantage of an early start. Journal of Economic Growth, 7 (4), 347-69.

Burnside, C., Eichenbaum, M. and Rebelo, S. (1995). Capital utilization and returns to scale. In NBER Macroeconomics Annual 1995, Volume 10, NBER Chapters, National Bureau of Economic Research, Inc, pp. 67-124.

Caballero, R. J., Hoshi, T. and Kashyap, A. K. (2008). Zombie lending and depressed restructuring in japan. American Economic Review, 98 (5), 1943-77.

Caselli, F. (1999). Technological revolutions. American Economic Review, 89 (1), 78-102.

- and Coleman, W. J. (2001). Cross-country technology diffusion: The case of computers. American Economic Review, 91 (2), 328-335.

Chari, V. V. and Hopenhayn, H. (1991). Vintage human capital, growth, and the diffusion of new technology. Journal of Political Economy, 99 (6), 1142-65.

Clark, G. (1987). Why isn't the whole world developed: Lessons from the cotton mills. The Journal of Economic History, 47 (1), 141-173.

Coe, D. T. and Helpman, E. (1995). International r\&d spillovers. European Economic Review, 39 (5), 859-887.

Cogley, T. and Nason, J. M. (1995). Output dynamics in real-business-cycle models. American Economic Review, 85 (3), 492-511. 
Comin, D. (2009). On the integration of growth and business cycles. Empirica, 36 (2).

- (2011). An exploration of the japanese slowdown during the 1990s. In A. K. K. Koichi Hamada and D. E. Weinstein (eds.), Japans Bubble, Deflation, and Long-term Stagnation, vol. 1, MIT Press, pp. 375-398.

-, Dmitriev, M. and Rossi-Hansberg, E. (2013). The Spatial Diffusion of Technology. Tech. rep.

- Easterly, W. and Gong, E. (2010). Was the wealth of nations determined in $1000 \mathrm{bc}$ ? American Economic Journal: Macroeconomics, 2 (3), 65-97.

- and Gertler, M. (2006). Medium-term business cycles. The American Economic Review, 96 (3), $523-551$.

- - - and Santacreu, A. M. (2009a). Technology Innovation and Diffusion as Sources of Output and Asset Price Fluctuations. NBER Working Papers 15029, National Bureau of Economic Research, Inc.

- and Hobisn, B. (2004). Cross-country technology adoption: Making theory face the facts. Journal of Monetary Economics, (51), 39-83.

— and - (2007). Implementing Technology. Tech. rep.

— and - (2009a). The CHAT Dataset. Working Paper 15319, National Bureau of Economic Research.

- and - (2009b). Lobbies and technology diffusion. Review of Economics and Statistics, 91 (2), 229-244.

- and - (2010). An exploration of technology diffusion. American Economic Review, 100 (5), 2031-59.

- - — and Rovito, E. (2006). Five Facts You Need to Know About Technology Diffusion. NBER Working Papers 11928, National Bureau of Economic Research, Inc.

- - - and - (2008a). A new approach to measuring technology with an application to the shape of the diffusion curves. The Journal of Technology Transfer, 33 (2), 187-207.

—, — and — (2008b). Technology usage lags. Journal of Economic Growth, 13 (4), 237-256.

-, Loayza, N., Pasha, F. and Serven, L. (2009b). Medium Term Business Cycles in Developing Countries. NBER Working Papers 15428, National Bureau of Economic Research, Inc. 
— and Mestieri, M. (2010). An intensive exploration of technology adoption. NBER Working Paper 16379.

— and - (2013). If Technology Has Arrived Everywhere, why has Income Diverged? Working Paper 19010, National Bureau of Economic Research.

-, Trumbull, J. G. and Yang, K. (2012). Fraunhofer: Innovation in Germany. Tech. Rep. 711-02, Harvard Business School Case.

Conley, T. G. and Udry, C. R. (2010). Learning about a new technology: Pineapple in ghana. American Economic Review, 100 (1), 35-69.

Cox, W. M. and Alm, R. (1996). The economy at light speed: technology and growth in the information age and beyond. Annual Report, pp. 2-17.

Crafts, N. (1997). Endogenous growth: Lessons for and from economic history. In D. Kreps and K. F. Wallis (eds.), Advances in Economics and Econometrics: Theory and Applications, vol. 2, CUP, pp. 38-78.

Davies, S. (1979). The Diffusion of Process Innovations. Cambridge University Press.

Diamond, J. (1999). Guns, germs, and steel: the fates of human societies. Norton paperback, W W Norton \& Company Incorporated.

Dixon, R. (1980). Hybrid corn revisited. Econometrica, 48, 145-146.

Dupas, P. (2009). What matters (and what does not) in households' decision to invest in malaria prevention? American Economic Review, 99 (2), 224-30.

Erosa, A., Koreshrova, T. and Restuccia, D. (2010). How important is human capital? a quantitative theory assessment of world income inequality. Review of Economic Studies, 77 (4), 1421-1449.

Evenson, R. E. and Gollin, D. (2003). Assessing the impact of the green revolution, 1960 to 2000. Science, $\mathbf{3 0 0}$ (5620), 758-762.

Fatas, A. (2000). Endogenous growth and stochastic trends. Journal of Monetary Economics, 45 (1), 107-128.

Ferejohn, J. (1986). Incumbent performance and electoral control. Public Choice, 50 (1), $5-25$.

Feyrer, J. (2009a). Distance, Trade, and Income The 1967 to 1975 Closing of the Suez Canal as a Natural Experiment. NBER Working Papers 15557, National Bureau of Economic Research, Inc. 
- (2009b). Trade and Income - Exploiting Time Series in Geography. NBER Working Papers 14910, National Bureau of Economic Research, Inc.

Foster, A. D. and Rosenzweig, M. R. (1995). Learning by doing and learning from others: Human capital and technical change in agriculture. Journal of Political Economy, 103 (6), 1176-1209.

- and - (2010). Microeconomics of technology adoption. Annual Review of Economics, $2(1), 395-424$.

Frankel, J. A. and Romer, D. H. (1999). Does trade cause growth? American Economic Review, 89 (3), 379-399.

Galí, J. (1999). Technology, employment, and the business cycle: Do technology shocks explain aggregate fluctuations? American Economic Review, 89 (1), 249-271.

Geroski, P. (2000). Models of technology diffusion. Research Policy, 29, 603-625.

Gort, M. and Klepper, S. (1982). Time paths in the diffusion of product innovations. Economic Journal, 92 (367), 630-53.

Griliches, Z. (1957). Hybrid corn: an exploration in the economics of technological change. Econometrica, 25 (4), 501-522.

- (1990). Patent statistics as economic indicators: A survey. Journal of Economic Literature, 28 (4), 1661-1707.

Guiso, L., Sapienza, P. and Zingales, L. (2008). Alfred marshall lecture social capital as good culture. Journal of the European Economic Association, 6 (2-3), 295-320.

Hannan, M. T. and Freeman, J. (1989). Organizations and social structure. Organizational Ecology, pp. 3-27.

James S. Coleman, E. K. and Menzel, H. (1966). Medical innovation: A diffusion study. Bobbs-Merrill Co.

Johansen, L. (1959). Substitution versus fixed production coefficients in the theory of economic growth: A synthesis. Econometrica, pp. 157-176.

Karshenas, M. and Stoneman, P. L. (1993). Rank, stock, order, and epidemic effects in the diffusion of new process technologies: An empirical model. The RAND Journal of Economics, pp. 503-528.

KELler, W. (2004). International technology diffusion. Journal of Economic Literature, $42(3), 752-782$. 
Kunicová, J. and Rose-AcKerman, S. (2005). Electoral rules and constitutional structures as constraints on corruption. British Journal of Political Science, 35, 573-606.

Kydland, F. E. and Prescott, E. C. (1982). Time to build and aggregate fluctuations. Econometrica, 50 (6), 1345-70.

Levin, S., Levin, S. and Meisel, J. (1987). A dynamic analysis of the adoption of a new technology: the case of optical scanners. Review of Economics and Statistics, (69), 12-17.

Lucas, R. E., Buera, F. J. and Alvarez, F. (2011). Trade and Idea Flows. 2011 Meeting Papers 984, Society for Economic Dynamics.

Maddison, A. (2004). Contours of the world economy and the art of macro-measurement 1500-2001. Ruggles Lecture.

Mansfield, E. (1961). Technical change and the rate of imitation. Econometrica, 29 (4), $741-766$.

- (1963). The speed of response of firms to new technologies. Quarterly Journal of Economics, 29 (77), 290-311.

- (1968). Industrial Research and Technological Innovation. W.W. Norton, New York.

Metcalfe, J. S. (1981). Impulse and diffusion in the study of technical change. Futures, 13 (5), 347-359.

- (1998). Evolutionary Economics and Creative Destruction. Routledge.

Mokyr, J. (1990). The Lever of Riches: Technological Creativity and Economic Progress. Oxford paperbacks, Oxford University Press, USA.

Myerson, R. B. (1993). Effectiveness of electoral systems for reducing government corruption: A game-theoretic analysis. Games and Economic Behavior, 5 (1), 118-132.

Nelson, R. R. and Phelps, E. S. (1966). Investment in humans, technological diffusion and economic growth. American Economic Review, 56 (1/2), 69-75.

Norbin, S. (1993). The relation between price and marginal cost in u.s. industry: A contradiction. Journal of Political Economy, 101 (6), 1149-64.

Olson, M. (1982). The Rise and Decline of Nations: Economic Growth, Stagflation and Social Rigidities. Yale university.

Peregrine, P. (2003). Atlas of cultural evolution. In World Cultures, 14, J.P. Gray. 
Perla, J., Tonetti, C. and Waugh, M. E. (2012). Equilibrium Technology Diffusion, Trade and Growth. Tech. rep., Mimeo.

Persson, T., Roland, G. and Tabellini, G. (2000). Comparative politics and public finance. Journal of Political Economy, 108 (6), 1121-1161.

-, Tabellini, G. and Trebir, F. (2003). Electoral rules and corruption. Journal of the European Economic Association, 1 (4), 958-989.

Porter, M. E. (1998). "clusters and the new economics of competition. Harvard Business Review, pp. 77-90.

Putterman, L. and Weil, D. N. (2010). Post-1500 population flows and the long-run determinants of economic growth and inequality. The Quarterly Journal of Economics, 125 (4), 1627-1682.

Riddell, W. C. and Song, X. (2012). The Role of Education in Technology Use and Adoption: Evidence from the Canadian Workplace and Employee Survey. IZA Discussion Papers 6377, Institute for the Study of Labor (IZA).

Romeo, A. (1975). Inter-industry and inter-firm differences in the rate of diffusion of an innovation. Review of Economics and Statistics, 57, 311-316.

Romer, P. M. (1990). Endogenous technological change. Journal of Political Economy, 98 (5), S71-102.

Rose, N. and Joskow, P. (1990). The diffusion of new technologies: evidence from the electric utility industry. The Rand Journal of Economics, (21), 354-373.

Sachs, J. and Warner, A. (1995). Economic Reform and the Progress of Global Integration. Harvard Institute of Economic Research Working Papers 1733, Harvard - Institute of Economic Research.

Santos, M. S. and Iraola, M. A. (2010). Long-Term Asset Price Volatility and Macroeconomic Fluctuations. 2010 Meeting Papers 374, Society for Economic Dynamics.

Scherer, F. (1981). Using linked patent and R\&D data to measure inter-industry technology flows. In Z. Griliches (ed.), R\&D, Patents, and Productivity, University of Chicago Press, pp. $417-464$.

Schmookler, J. (1966). Invention and economic growth. Harvard University Press.

Seshadri, A. and Manuelli, R. (2005). Human Capital and the Wealth of Nations. 2005 Meeting Papers 56, Society for Economic Dynamics. 
Skinner, J. and Staiger, D. (2007). Technology adoption from hybrid corn to beta-blockers. In Hard-to-Measure Goods and Services: Essays in Honor of Zvi Griliches, NBER Chapters, National Bureau of Economic Research, Inc, pp. 545-570.

Solow, R. M. (1956). A contribution to the theory of economic growth. The Quarterly Journal of Economics, 70 (1), 65-94.

- (1960). Investment and technical progress. In S. K. K. Arrow and P. Suppes (eds.), Mathematical Methods in the Social Sciences, vol. 1, Stanford University Press, pp. 89-104.

Spolaore, E. and Wacziarg, R. (2009). The diffusion of development. The Quarterly Journal of Economics, 124 (2), 469-529.

Stoneman, P. (1981). Intra-firm diffusion, bayesian learning and profitability. Economic Journal, 91 (362), 375-88.

- (1983). The economic analysis of technological change. Oxford University Press Oxford.

— (1987). The economic analysis of technology policy. Clarendon Press Oxford.

- et al. (1995). Handbook of the economics of innovation and technological change. Blackwell Oxford.

Tabellini, G. (2007). Institutions and Culture. Working Papers 330, IGIER (Innocenzo Gasparini Institute for Economic Research), Bocconi University.

Thirtle, C. and Ruttan, V. (1987). The Role of Demand and Supply in the Generation and Diffusion of Technical Change. Fundamentals of Pure and Applied Economics Series, Harwood Academic Publications.

Vickery, G. and Northcott, J. (1995). Diffusion of microelectronics and advanced manufacturing technology: A review of national surveys. Economics of Innovation and New Technology, 3 (3-4), 253-276.

\section{A Description of Technologies used to Estimate Diffusion Curves}

The twenty-five particular technology measures, organized by broad category (transportation, communication, IT, industrial, agricultural and medical) are described below.

Transportation 
1. Steam and motor ships: Gross tonnage (above a minimum weight) of steam and motor ships in use at midyear. Invention year: 1788; the year the first (U.S.) patent was issued for a steam boat design.

2. Railways - Passengers: Passenger journeys by railway in passenger-KM.

Invention year: 1825; the year of the first regularly schedule railroad service to carry both goods and passengers.

3. Railways - Freight: Metric tons of freight carried on railways (excluding livestock and passenger baggage).

Invention year: 1825; same as passenger railways.

4. Cars: Number of passenger cars (excluding tractors and similar vehicles) in use. Invention year: 1885; the year Gottlieb Daimler built the first vehicle powered by an internal combustion engine.

5. Trucks: Number of commercial vehicles, typically including buses and taxis (excluding tractors and similar vehicles), in use. Invention year: 1885; same as cars.

6. Tractor: Number of wheel and crawler tractors (excluding garden tractors) used in agriculture. Invention year: 1892; John Froelich invented and built the first gasoline/petrolpowered tractor.

7. Aviation - Passengers: Civil aviation passenger-KM traveled on scheduled services by companies registered in the country concerned. Invention year: 1903; The year the Wright brothers managed the first successful flight.

8. Aviation - Freight: Civil aviation ton-KM of cargo carried on scheduled services by companies registered in the country concerned. Invention year: 1903; same as aviation - passengers.

\section{Communication and IT}

1. Telegraph: Number of telegrams sent. Invention year: 1835; year of invention of telegraph by Samuel Morse at New York University.

2. Mail: Number of items mailed/received, with internal items counted once and crossborder items counted once for each country. Invention year: 1840; the first modern postage stamp, Penny Black, was released in Great Britain.

3. Telephone: Number of mainline telephone lines connecting a customer's equipment to the public switched telephone network. Invention year: 1876; year of invention of telephone by Alexander Graham Bell. 
4. Cellphone: Number of users of portable cell phones. Invention year: 1973; first call from a portable cellphone.

5. Personal computers: Number of self-contained computers designed for use by one person. Invention year: 1973; first computer based on a microprocessor.

6. Internet users: Number of people with access to the worldwide network. Invention year: 1983; introduction of TCP/IP protocol.

\section{Industrial}

1. Spindles: Number of mule and ring spindles in place at year end. Invention year: 1779; Spinning Mule invented by Samuel Crompton.

2. Synthetic Fiber: Weight of synthetic (noncellulosic) fibers used in spindles Invention year: 1924; Invention of rayon.

3. Steel: Total tons of crude steel production (in metric tons). This measure includes steel produced using Bessemer and Open Earth furnaces. Invention year: 1855; William Kelly receives the first patent for a steel making process (pneumatic steel making).

4. Electric Arc Furnaces: Crude steel production (in metric tons) using electric arc furnaces. Invention year: 1907; invention of the Electric Arc Furnace.

5. Blast Oxygen Furnaces: Crude steel production (in metric tons) in blast oxygen furnaces (a process that replaced Bessemer and OHF processes). Invention year: 1950; invention of Blast Oxygen Furnace.

6. Electricity: Gross output of electric energy (inclusive of electricity consumed in power stations) in Kw-Hr. Invention year: 1882; first commercial power station on Pearl Street in New York City.

Agricultural

1. Fertilizer: Metric tons of fertilizer consumed. Aggregate of 25 individual types, corresponding to broadly Ammonia and Phosphates. Invention year: 1910; Haber-Bosch process to produce ammonia is patented in 1910 .

2. Harvester: Number of selfpropelled machines that reap and thresh in one operation. Invention year: 1912; The Holt Manufacturing Company of California produces a selfpropelled harvester. Subsequently, a selfpropelled machine that reaps and threshes in 
one operation appears.

Medical

1. Kidney Transplant: Number of kidney transplants performed. Invention year: 1954; Joseph E. Murray and his colleagues at Peter Bent Brigham Hospital in Boston performed the first successful kidney transplant.

2. Liver Transplant: Number of liver transplants performed. Invention year: 1963; Dr. Thomas Starzl performs the first successful liver transplant in the United States.

3. Heart Transplant: Number of heart transplants performed Invention year: 1968; Adrian Kantrowitz performed the first pediatric heart transplant in the world on December 6, 1967 at Maimonides Hospital.

\section{B Additional Tables}




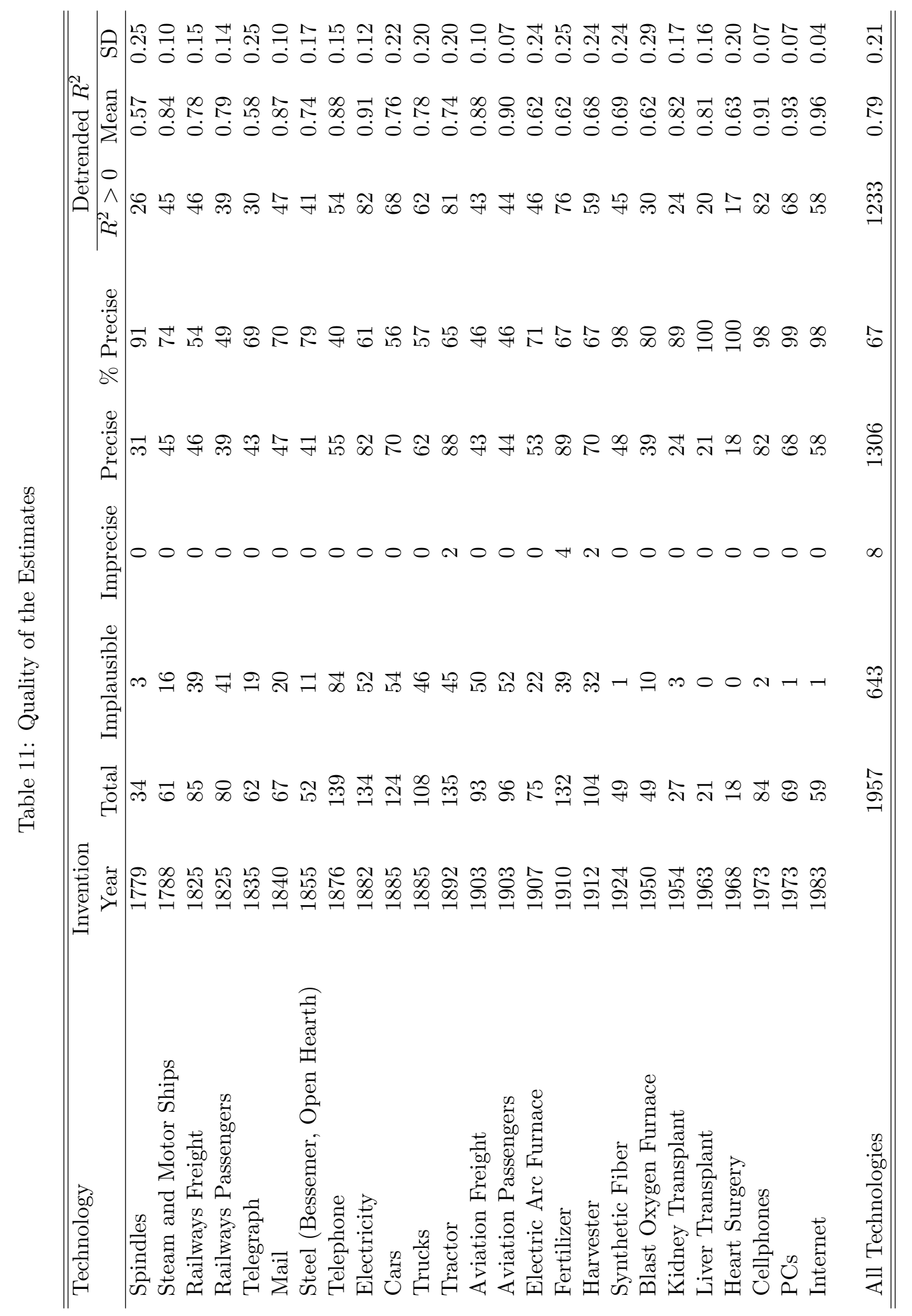

